\title{
Determinantes externos del crecimiento económico en El Salvador 1962-19881
}

\author{
Alvaro Trigueros \\ Rafael Antonio Solorzano \\ Ena Elizabeth Cuestas
}

El objetivo central de este artículo es demostrar que dado el carácter trunco y dependiente del aparato productivo de la economia salvadorena, la dependencia extrema de las exportaciones de café y la elevada concentración de los ingresos, la evolución de factores extemos que dependen de la dinámica de los mercados mundiales de bienes y de capitales, determinan el crecimiento económico.

Más en concreto, partimos del hecho de que en nuestro pais existe una estructura productiva interna, sumamente dependiente de las importaciones de insumos y bienes de capital, y de la dinámica de las exportaciones para poder sostener un crecimiento económico, para evidenciar y cuantificar los mecanismos concretos a través de los cuales el sector externo se convierte en un determinante del crecimiento económico en el pais a lo largo del periodo 1962-1988.

En este sentido, llegamos a explicar y cuantificar cómo el ahorro externo (financiamiento, donaciones, inversión extranjera directa y las transferencias) llega a constituirse en un elemento de gran relevancia dentro de los determinantes del crecimiento económico de El Salvador a lo largo de los anos en estudio. Más específicamente, demostramos que en la década de los ochenta el ahorro externo se convierte en un factor clave, que permite aumentar la capacidad de importación de bienes necesarios para el funcionamiento de la economia por encima de 
las exportaciones, to que a su vez posibilita sostener el crecimiento económico.

También, se llega a demostrar y cuantificar en el trabajo que la dinámica de las exportaciones salvadorenas, está determinada no únicamente por la demanda externa sino que también por la capacidad interna de producción, y que dada la enorme apertura de la economía salvadorefia, las exportaciones, como factor fundamental que permiten el acceso a las divisas, como un elemento de la demanda internacional que se convierten en dinamizador de la producción, y como un factor generador de ingresos con elevada elasticidad ingreso del ahorro, es una variable que determina el crecimiento económico.

Por otra parte, la importancia de estos puntos radica en el hecho de que cualquier intento de desarrollo económico, tiene que pasar necesariamente por un proceso de crecimiento en la producción real, entre otros factores, y para lograr ésto último se debe de tener en cuenta cuál es el margen de acción de la política económica que permiten las variables que están fuera del control de la economía salvadorena y cómo éstas ejercen sus limitaciones sobre los procesos de producción interna, cosas que se deben de tener en cuenta en cualquier proceso de concertación nacional.

De acuerdo a to anterior este trabajo se desarrolla de la siguiente manera. En la primera parte hacemos una exposición breve de los enfoques que utilizamos como base para la construcción de un modelo econométrico. Estos son, el modelo de las dos brechas, un modelo keynesiano de crecimiento económico con restricción externa, y el enfoque de la CEPAL junto con algunos aportes de Kalecki. En la segunda parte se presenta la especificación del modelo en su conjunto y particularmente las ecuaciones que lo componen, las relaciones y resultados que se esperan obtener en la verificación empírica. La tercera parte consiste en la estimación econométrica del modelo especificado en la sección anterior, a la vez que se presentan los análisis estadísticos, econométricos y económicos de los resultados que se obtuvieron, haciendose también un análisis histórico de las relaciones entre las principales variables que se manejan en el modelo. tratando de destacar los elementos importantes en cada periodo.

Finalmente exponemos las conclusiones a las que llegamos en la investigación y junto con ellas se dan algunas recomendaciones de política económica relacionadas con el problema. 
I. Tres enfoques sobre el crecimiento económico y la brecha del sector externo

En este capitulo hacemos una breve exposición de los tres enfoques mencionados en la introducción, el modelo de las dos brechas, el enfoque keynesiano y el estructuralista, para abordar teóricamente el problema de los determinantes externos sobre el crecimiento económi$c 0$. En la primera parte hacemos una breve exposición del modelo de las dos brechas. En la segunda parte, presentamos un enfoque keynesiano sobre el problema del crecimiento económico para una economia abierta. Y finalmente, abordamos el problema desde una perspectiva estructuralista, combinándola con algunos de los aportes de Michal Kalecki.

\section{A. El modelo de las dos brechas}

A continuación haremos una breve exposición del modelo de las dos brechas comenzando por una descripción intuitiva del enfoque.

De acuerdo a Taylor (1983 y 1986) la noción básica de estrangulamiento debido a rigideces en el sector externo de la economla tiene sus orlgenes en las ideas propuestas por los economistas estructuralistas latinoamericanos y en una exposición temprana del problema por parte de Hirschman. Luego este modelo, en su versión más simplificada, fue formalizado por primera vez por Chenery y Buno (1962), Chenery y Strout (1968) y por McKinnon (1964). En esta sección solamente haremos una presentación intuitiva del modelo planteado por dichos autores, siguiendo un articulo de Marshall (1970).

Este enfoque parte de dos conceptos básicos de macroeconomia: la deficiencia de ahorros con respecto a la inversión y el déficit del sector externo. ${ }^{2}$ Tal como se presenta en las identidades de contabilidad nacional ambas brechas son iguales. El producto nacional se expresa $c 0-$ mo:

donde:

$$
Y=C+I+X-M
$$
Y: Producto nacional
C: Consumo público y privado
I: Inversión pública y privada
$X$ : Exportaciones; $y$
M: Importaciones

Partiendo del concepto convencional que el ahorro, $S$, es toda aquella parte de la renta que no se gasta en consumo tenemos que: 


$$
Y-C=S
$$

Sustituyendo (2) en (1) y ordenando términos, tenemos:

$$
(M-X)=(I-S)
$$

que es la identidad macroeconómica que relaciona el sector externo y el sector nacional. El exceso de inversión sobre el ahorro es financiado con el déficit del sector externo. Esto último implica que dicha economía puede hacer uso del ahorro externo.

Ahora bien, desde el punto de vista del modelo de las dos brechas esto no implica que las magnitudes ex-ante de ambos desequilibrios tengan que ser iguales, sino que pueden ser diferentes, ya que no necesariamente son funciones de las mismas variables, y si lo fueran no tienen por que tener el mismo valor de los parámetros. Al igual que en el modelo de una economía cerrada, la inversión es igual al ahorro, pero sus magnitudes ex-ante no son necesariamente iguales.

En este sentido, podemos encontrar dos factores limitantes del monto de inversiones, la insuficiencia de ahorro interno y/o la falta de disponibilidad de divisas.

Para ilustrar estas ideas tomamos el ejemplo de Marshall (1970). LLamemos a la brecha de comercio $B c=(M-X)$, y a la brecha de ahorro $B s=(I-S)$. Un pais determinado para poder crecer a $5 \%$ necesita importar insumos por un valor de 80 e invertir por un valor de 100. Si, al mismo tiempo, los ingresos no generaran un ahorro mayor que 60 y el pals no pudiera exportar más que 30 , se darian como magnitudes ex ante, dos brechas diferentes:

$$
\begin{aligned}
& B s=100-60=40 \\
& B C=80-30=50
\end{aligned}
$$

Si no existiera financiamiento externo y si no hubiera reservas disponibles, entonces la inversión no podria ser mayor que el ahorro, y las importaciones no podrian ser mayores que las exportaciones. En este caso las dos brechas ex-post se igualan a cero. Bajo tales circunstancias la economia no podrá crecer al $5 \%$ anual.

Si una importación de 30 permite una tasa de crecimiento de $2 \%$, y una inversión de 60 permite una tasa mayor, las importaciones serán el factor limitante del crecimiento económico. Por lo tanto, el pais estaria dejando de utilizar parte de su ahorro potencial, ya que, para crecer al ano a dicha tasa de $2 \%$, no necesita una cantidad de inversión tan 
grande como la que podría realizar, y además por la falta de divisas no se podría llevar a cabo.

Por otra parte, si existiera un financiamiento externo de 50, que es ol monto necesario para cubrir la brecha mayor, que en este caso es la de la balanza comercial, el pais podrá crecer a la tasa de $5 \%$, y podrá realizar importaciones por un valor de 80 , pero siempre tendria un ahorro potencial inutilizado, ya que ahora la inversión seria financiada con ahorro interno por un valor de 50 y con ahorro externo por un valor lqual. Ex post, en este caso, las dos brechas también son iguales.

Ahora bien, en el caso que la brecha dominante fuera la del ahorro, el país tendría capacidad para realizar importaciones por un monto mayor que el necesario para mantener una determinada tasa de crecimiento. En tales circunstancias habrá importaciones superfluas, ya sea que las dos brechas ex-post se igualen a cero, o que hubiera un ingreso de capital que cubriera la brecha del ahorro.

A continuación, siguiendo siempre a Marshall (1970), haremos una exposición formal del modelo de las dos brechas, especificando las funciones de las variables que participan y las condiciones de equilibrio del modelo. Vamos a suponer que el consumo, al igual que el ahorro, es función del ingreso, que las importaciones son función de la inversión; la producción es función de la inversión, mientras que las exportaciones son exógenas. En términos de ecuaciones el modelo se puede plantear de la siguiente forma:

$\begin{array}{ll}S=f(Y) & \begin{array}{l}\text { función de ahorro } \\ \text { función de importación } \\ \text { función de producción }\end{array} \\ Y=h(I) & \text { exportaciones exógenas } \\ X=X & \begin{array}{l}\text { definición del ingreso } \\ \text { condición de equilibrio (1) } \\ Y=C+I+X-M\end{array} \\ I=S+(M-X) & \begin{array}{l}\text { condición de equilibrio (2) donde } F \\ \text { es la brecha realizada (entrada neta } \\ \text { de capital extranjero) }\end{array} \\ M=X+F & \end{array}$

La condición de equilibrio (1) expresa la necesidad de que exista un equilibrio entre la disponibilidad y los requerimientos de recursos, y la condición (2) expresa la necesidad de equilibrar la balanza de pagos. Ambas condiciones no tienen por qué operar simultáneamente, tal y como lo expusimos arriba, solamente una de las brechas es dominante. 
Si $(M-X)=B C>(I-S)=B s$, la brecha externa es dominante; y al revés, sl Bs $>$ BC. Para aplicar de forma sencilla el modelo anterior, supongamos que las ecuaciones de comportamiento son lineales:

$$
\begin{aligned}
S & =b_{1} Y \\
M & =b_{2} l \\
\Delta Y & =b_{3} I
\end{aligned}
$$

donde, $b_{1}$ es la propensión marginal a ahorrar, $b_{2}$ es la propensión marginal a importar respecto a la inversión, y $b_{3}$ es la relación marginal de producto a capltal.

SI susthulmos la ecuación (4) en la condición (1), podemos expresar la brecha del ahorro de la siguiente forma:

$$
I-b, Y=F
$$

luego sustituimos I por su valor de la ecuación (6):

$$
\frac{\Delta Y}{b_{3}} \cdot b_{1} Y=F
$$

Dividlendo todo por Y:

De donde se obtiene:

$$
\frac{\Delta Y}{b_{3} Y}-b_{1}=\frac{E}{Y}=f
$$

$$
\frac{\Delta Y}{Y}=b_{1} b_{3}+b_{3} f
$$

Esta ecuación nos indica que el crecimiento económico es función de la proporción del flujo neto de capital externo con la producción nacional cuando la brecha del ahorro es dominante.

Por otra parte, si en la condición (2) sustituimos el valor de las importaciones expresado en la ecuación (5) obtendremos la brecha del sector extemo:

$$
b_{2} I=X+F
$$


wego remplazamos el valor de la inversión representado en la ecuación (6):

$$
\begin{aligned}
& \underline{b}_{g} \\
& b_{3}
\end{aligned}
$$

y finalmente dividimos ambos lados de la ecuación por $Y$ y despejamos $\Delta Y \Gamma$, obteniendo:

$$
\frac{\Delta Y}{Y}=\underline{b}_{3} X+\underline{b}_{3} Y
$$

Esta ecuación nos dice que la tasa de crecimiento del ingreso es función de la proporción del flujo neto de entradas de capital extranjero en relación al ingreso y de la participación de las exportaciones en el mismo, cuando la brecha comercial es dominante.

Observando las ecuaciones (Bs) y (Bc), vemos que ambas nos indican que la tasa de crecimiento esta relacionada con la brecha relativa f. La primera expresa la condición limitativa del ahorro; y la segunda, el problema de la restricción externa al crecimiento económico reflejado en la capacidad para importar.

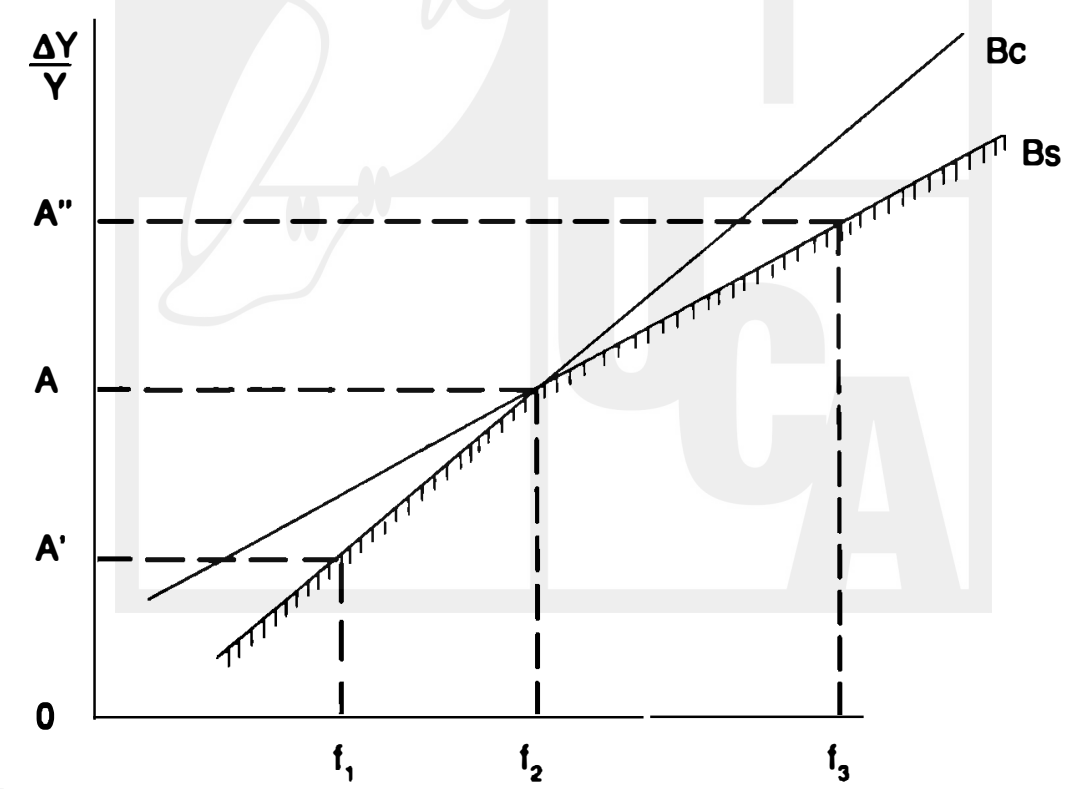

Flgure 1: Tasa de crecimiento económico cuando existe restricción del ahorro y cuando existe restricción externa. 
Ambas ecuaciones las podemos expresar gráficamente (ver Figura 1). En el caso del crecimiento económico cuando la brecha del ahorro es dominante la pendiente de la recta de crecimiento será menor, ya que el financiamiento externo obtenido se estará utilizando tanto para importar productos suntuarios como para cubrir los requerimientos de ahorro para inversión. En la otra situación, cuando el crecimiento económico se da bajo el dominio de la brecha comercial, la pendiente de la recta será mayor, ya que el financiamiento externo que entra estará siendo utilizado únicamente para cubrir las necesidades de importación.

Supongamos que la meta de crecimiento sea una tasa equivalente a $O A^{\circ}$. En este caso, vemos que la restricción externa es dominante, y para lograr dicha tasa de crecimiento,sería necesario una inyección de flujos de capital externo equivalente a $f_{1}$. En este caso quedaria una parte de ahorro frustrado que no podria realizarse.

De otra forma, si la tasa de crecimiento deseada fuera OA", la brecha dominante seria la del ahorro, y por lo tanto la tasa relativa de flujos de capital externo tendrá que llegar a $f_{3}$. Como en este caso la brecha del comercio estaria más que cubierta, se producirán importaciones sunturias.

Finalmente, como lo sefiala McKinnon (1964), si la economia va creciendo a tasas superiores a las cuales se lo permite su propia estructura económica, utilizando financiamiento externo, con el tiempo el volumen absoluto de la producción será mucho mayor, y por tanto, para mantener cierta tasa relativa de flujos de capital externo, $f=F / Y$, en términos de volumen éstos tendrán que crecer también, $F=f Y$. Sin embargo el acceso al financiamiento externo no es ilimitado, por lo cual la economia tiene que ir buscando las formas de ir reduciendo las necesidades de financiamiento externo mediante la sustitución de importaciones y/o la promoción de exportaciones (reflejándose en el traslado hacia arriba y hacia la izquierda de la recta BC) y el incremento en el esfuerzo de ahorro. De lo contrario la economia tarde o temprano perderá la solvencia financiera necesaria (crisis de la deuda) para ser un receptor de capital extranjero, y en estas circunstancias la tasa de crecimiento y el volumen de producción tienen que ajustarse a la restricción externa.

\section{B. Un enfoque keyneslano}

En esta sección haremos una breve exposición del modelo de Thirlwall y Hussain sobre crecimiento económico con restricción externa. EI trabajo de dichos autores parte de bases keynesianas, utilizando un modelo que Sir Roy Harrod desarrolló en 1933. 
Para Thirlwall y Hussain, entre los supuestos originales de Harrod, tenemos que los términos de intercambio son constantes, que no hay ahorro e inversión y que tampoco existe actividad por parte del goblemo. Si otros gastos inducidos y salidas del flujo circular del ingreso se compensan entre si a nivel agregado, es decir, que no producen ningún efecto sobre el equilibrio de la balanza de pagos, y si a la vez por una u otra razón el equilibrio en la balanza de pagos es objetivo de política económica, de tal manera que el nivel y el crecimiento del inoreso tiene por necesidad que restringirse en el largo plazo para mantener el equilibrio entre exportaciones e importaciones, entonces se puede demostrar que la tasa de crecimiento económica va a estar restringida por la regla simple: $y=x / \pi$, donde $y$ es la tasa de crecimiento de la producción, $x$ es la tasa de crecimiento de las exportaciones y $\pi$ es la elasticidad ingreso de las importaciones. Supuesto que se preserva el equilibrio de la balanza en cuenta corriente y que los términos reales de intercambio permanecen estables.

Existen únicamente dos factores que pueden causar que la tasa de crecimiento de un pais se desvie de esta tasa:

1. Las variaciones en los términos de intercambio, y

2. Los flujos de capital, permitiendo una diferencia entre gasto doméstico e ingreso y un desequilibrio en la cuenta corriente.

Teniendo en cuenta esos dos factores, y si además le asignamos a las exportaciones y las importaciones funciones de comportamiento específicas. Siendo las exportaciones función de la relación de los términos de intercambio, del tipo de cambio y de la demanda extranjera, y las importaciones función de la relación de los términos de intercambio, del tipo de cambio y del ingreso nacional obtenemos la siguiente tasa de crecimiento restringida por la balanza de pagos si se parte de un desequilibrio inicial:

$$
\frac{y b_{1}=((P d X / R) \cap+\mu)(p d-e-p f)+(p d-p f-e)+P d X / R(\varepsilon(z))+C / R(c-p d)}{\pi}
$$

Donde Pd es el precio doméstico, $X$ es el volumen de exportaciones, $R$ es el flujo de divisas hacia el país ya sea por exportaciones o por flujos netos de capital, $\cap$ es la elasticidad términos de intercambio de la demanda de exportaciones, $\mu$ es la elasticidad términos de intercambio de la demanda de importaciones, pd es el crecimiento de los precios domésticos, e es el crecimiento del tipo de cambio, pf es el crecimiento de los precios extranjeros, $\varepsilon$ la elasticidad ingreso intemacional de la demanda de exportaciones, $z$ el el crecimiento del ingreso inter- 
nacional, c es el crecimiento de los flujos netos de capital y $\pi$ sigue siendo la elasticidad ingreso de la demanda de importaciones.

En esta ecuación, el primer término del lado derecho da el efecto volumen de los cambios de precios relativos sobre el crecimiento del ingreso real limitado por la balanza de pagos; por ejemplo, un crecimiento mayor de los precios domésticos en relación a los precios extranjeros, puede afectar el crecimiento de las exportaciones y las importaciones, disminuyendo las primeras y aumentando las segundas, restringiendo asi el crecimiento económico. El segundo término da el efecto puro de los términos de intercambio; por ejemplo un deterioro de los términos de intercambio disminuye el poder de compra de nuestras exportaciones en relación a las importaciones, restringiendo el crecimiento. El tercer término da el efecto exógeno de cambios en el crecimiento del ingreso en el exterior; por ejemplo si aumenta la demanda externa de nuestras exportaciones, se podrán financiar más importaciones aumentado las posibilidades de crecimiento. $Y$ el último término da el efecto de la tasa de crecimiento de los flujos netos de capital, si estos aumentan, el crecimiento económico podrá ser mayor.

\section{El enfoque estructurallsta y algunos aportes de kaleckl}

Tanto el modelo de las dos brechas como el keynesiano abordan la relación entre las exportaciones y las importaciones con el crecimiento económico de una forma bastante técnica, mientras que el enfoque de la CEPAL versa más sobre las causas que llevan al sector extemo de las economias latinoamericanas a conventirse en una restricción al crecimiento dadas las caracteristicas que presentan éstas, como lo son: poseer una economia trunca en el sentido de que "carece de los sectores productores de bienes de capital", ${ }^{3}$ heterogeneidad de los mercados internos, diferente elasticidad ingreso de la demanda de importaciones de nuestros paises y los desarrollados, y la dependencia de uno o pocos productos de exportación.

Dadas las caracteristicas de nuestras economias, la búsqueda de un desarrollo económico puede crear problemas en la balanza de pagos, esto porque se hace necesario realizar importaciones para llevar adelante el proceso, y las exportaciones no crecen al mismo ritmo que éstas.

Por el lado de las importaciones, tenemos que nuestras economias tienen que recurrir a éstas de manera creciente debido a la gran dependencia de insumos y bienes de capital del aparato productivo, a la tendencia a imitar los patrones de consumo del centro y a las rigidices de algunos sectores, como el agrícola productor de granos básicos, 10 
que tiene como consecuencia una elevada elasticidad ingreso de nuestras importaciones.

Por otra parte las exportaciones tienden a crecer lentamente debido a la escasa diversificación que tienen nuestras economias en cuanto a los productos de exportación y el lento ritmo de crecimiento de éstos. Esto se debe a que esos productos son esencialmente agricolas y no somos los únicos que los ofrecemos en el mercado mundial; por lo tanto se nos impone desde el exterior el precio a que se venderá, salvo en casos especiales como el del petróleo, donde son los paises productores de este rubro los que determinan en gran parte los precios a través de la OPEP. Esta especialización que presenta nuestro sector exportador -sobre todo de productos del agro- hace que no tengamos mayor capacidad de obtener divisas y poder conseguir los productos que no producimos al interior de nuestra economia.

Todas estas limitantes para exportar, aunadas a la imposibilidad de reducir nuestras importaciones, nos lleva a estar en un constante desequilibrio externo. Por lo tanto esa rigidez que presentan las importaciones para bajar su nivel, tienden a impedir que la industrialización y el crecimiento del producto evolucionen a un ritmo adecuado, supeditando ese crecimiento al ritmo con que lo hagan las exportaciones, que como vimos arriba es muy lento, a menos que se incurra en deuda externa, lo que a largo plazo se vuelve contraproducente.

\section{El aporte de Kaleckl.}

El desarrollo teórico que hace Kalecki $(1980)^{4}$ es muy parecido al desarrollado por los estructuralistas de la CEPAL, pero leyendo detenidamente se pueden rescatar algunos aspectos importantes, que es 10 que exponemos en esta sección.

En uno de sus articulos, ${ }^{5}$ Kalecki trata sobre cuáles son los diferentes mecanismos para el financiamiento del desarrollo económico. Este autor comienza por el análisis de una economia cerrada para poder determinar las condiciones elementales que permiten el crecimiento; para esto plantea la existencia de dos sectores, uno productor de bienes de capital y otro productor de bienes de consumo identificado más con la agricultura. Sostiene que de ejercerse un crecimiento en el primer sector, con fines de desarrollo económico el otro sector deberá crecer al mismo ritmo, y de lograrse esto, no habria ningún problema dado que la demanda de bienes de consumo generada por el aumento del empleo, no ejercerla ninguna presión sobre los precios de éstos productos porque ésta es satisfecha,si se supone una oferta elástica en el sector productor de bienes de consumo. En estas condiciones la inversión ge- 
neraría su propio ahorro para el financiamiento, igual que en los modelos keynesianos, al crecer la producción crece el ingreso, y al crecer éste último crece el ahorro.

Por lo tanto no existe ningún limitante financiero al volumen de inversión; el problema real es si ese financiamiento crea o no presiones inflacionarias.

Un primer problema para el financiamiento del desarrollo económico surge cuando el sector agricola no logra responder a las demandas de bienes de consumo como resultado del crecimiento en el otro sector. En este caso, se generará un incremento en los precios de los bienes de consumo, hasta que el valor de la oferta (que en términos reales es la misma) en éste sector se iguale al nuevo nivel de demanda, experimentándose una reducción en los salarios reales, y el financiamiento de la inversión provendrá por tanto de una transferencia de recursos por el ahorro forzoso que esto genera.

Ahora bien, este problema de la rigidez en el sector agrícola puede resolverse una que vez que consideramos una economia abierta, pero a la vez se traslada a otro sector. Asi tenemos, que para satisfacer los incrementos en la demanda de bienes alimenticios, el país en cuestión puede recurrir a las importaciones de éstos, evitando que los precios suban, pero provocando una presión sobre la balanza comercial, que unida a las dificultades ya mencionadas antes por la teoría de la CEPAL, to único que logra es agravar el desequilibrio externo. Este desequilibrio externo, ex-post,puede ser solventado según Kalecki(1953) por el financiamiento externo, a través de donaciones, préstamos, inversión extranjera directa, 6 como en el caso salvadoreno transferencias por remesas de los familiares en el extranjero fundamentalmente en la última década. Al recurrir a este tipo de financiamiento, lo que se logrará es realizar un mismo nivel de inversión con una menor cantidad de ahorro interno, disminuyendo por lo tanto la presión sobre la oferta de bienes de consumo, provenientes del crecimiento del sector productor de bienes de capital.

"Esto significa que la transformación de la estructura productiva en favor de los sectores no agrícolas no puede realizarse sino se aumenta la produoción agrícola misma... a riesgo de provocar inflación o déficit en la balanza de pagos."

\section{Un modelo de crecimlento económico con restricción externa}

En esta sección construimos nuestro propio modelo de crecimiento con restricción externa tomando en cuenta las características estructu- 
rales de nuestra economia y los tres enfoques que abordamos en la sección precedente, asi como también, las críticas que se han hecho a los diversos estudios empiricos realizados previamente, que tratan de aplicar el modelo de las dos brechas.?

En concreto, el modelo que desarrollamos más adelante, es de carácter simultáneo y consta de cuatro ecuaciones de comportamiento para cada una de las siguientes variables: el ahorro, las importaciones, las exportaciones y la tasa de crecimiento de la producción, más dos indentidades, una para la inversión y otra para el ahorro externo.

El modelo nos refleja los vínculos entre todas estas variables, cómo interactuaan entre sí, poniendo en evidencia cuáles son los mecanismos especificos a través de los cuales el sector externo se convierte en un determinante clave para el crecimiento económico.

A continuación describimos cada una de las ecuaciones de comportamiento, y posteriormente damos una visión global del modelo.

\section{La funclón ahorro}

Tal y como vimos en el modelo de las dos brechas, el ahorro es función del ingreso. Sin embargo, dicha relación resulta extremadamente simplificada para llevarla a la contrastación empírica. Nosotros ampliamos la especificación de la función del ahorro tomando en cuenta las caracteristicas estructurales de nuestra economia. Por ejemplo, el hecho de la gran apertura de nuestra economia al comercio exterior, que las exportaciones de nuestro pais dependen mucho del café, y que los ingresos que éstas generan son bastantes concentrados.

En efecto, trabajos tales como el de Papanek (1973) explican que el ahorro en los paises subdesarrollados es función de las exportaciones, especialmente de los paises muy dependientes del sector exportador. Las razones para tal dependencia son que las exportaciones producen generalmente ingresos altamente concentrados, especialmente en el caso de las exportaciones primarias como el café. $Y$ además, las exportaciones son administrativa y políticamente fáciles de carga impositiva, tal y como vimos en el apartado anterior, por lo que facilitan elevadas tasa de ahorro gubemamental. Por lo tanto, la teoria convencional del ahorro nos lleva a esperar elevadas elasticidades a ahorrar respecto a tales ingresos.

Los trabajos de Maiselz (1968), Lee(1971) y Laumas (1982) agregan otras razones. Entre éstas que el crecimiento sostenido en las exportaclones puede resultar en el crecimiento de la propensión marginal a ahorrar en otros sectores. Las exportaciones incrementarlan el ahorro 
por la mejor asignación de recursos inducida por las oportunidades del comercio, tal como lo sugiere la teoria clásica. Y,también por el multiplicador del comercio exterior como lo sugiere la teoria keynesiana.

Además, para Chenery y Eckstein (1970) esta relación es coherente dentro del modelo de las dos brechas, cuando la brecha del comercio es dominante. En este caso las divisas son un factor escaso, y dado que la inversión es altamente dependiente de las importaciones, las oportunidades de inversión doméstica van a variar cercanamente con la disponibilidad de divisas, y el ahorro doméstico puede esperarse, por tanto, que varie en respuesta a aquellas oportunidades. En estas circunstancias se esperaria que las entradas de divisas por exportaciones tengan un efecto positivo sobre el ahorro.

Todas las razones anteriores sobre la relación exportaciones-ahorro justitican la separación de los ingresos de la economia, entre ingresos del sector no exportador y del sector exportador, tal como lo sugirió inicialmente Maizels (1968). Esperándose que la elasticidad ingreso del ahorro sea más alta en el sector exportador.

Por otra parte, una de las principales críticas al modelo de las dos brechas, nos dice que no se consideran los efectos del servicio de la deuda (intereses y amortización) sobre el crecimiento económico. Nosotros incluímos dicha variable, (A), sobre la base de que en el momento que la deuda comienza a ser pagada, parte de los ingresos generados por nuestra economia, deben ser retirados para cumplir con el compromiso, y por tanto el ingreso que queda disponible para consumir y ahorrar es menor, afectando las posibilidades de acumulación de la economia. La diferencia entre este modelo y otros, ${ }^{8}$ es que no toma en cuenta únicamente los intereses o la tasa de interés como indicador de la carga de la deuda, sino que también el servicio, es decir, las amortizaciones y los intereses.

Finalmente, en un pais pequeno como el nuestro, el ahorro está determinado por variables que están fuera del control de las autoridades económicas, tal como lo senala Cáceres (1990). Así tenemos que el ahorro también es función negativa de la tasa real de interés internacional, REU, dado que una alta tasa de interés estimula la fuga de capitales al exterior, por una mayor rentabilidad y por colocar los fondos de ahorro en un lugar más seguro. En nuestro modelo, nosotros utilizaremos la tasa de interés de Estados Unidos, dadas las estrechas relaciones entre este país y el nuestro.

La función ahorro de nuestro modelo se especifica de la siguiente manera: 


$$
\ln \left(S_{1}\right)=\theta_{0}+\theta_{1} \ln \left(Y_{1}-X_{1}\right)+\theta_{2} \ln \left(X_{1} Y_{1}\right)-e_{3} \ln \left(A_{1}\right)-\theta_{4} \ln \left(R E U_{1}\right)
$$

donde el ahorro real, $S_{1}$ es función del ingreso real del sector no exportador, $\left(Y_{1}-X_{1}\right)$, de la participación del ingreso del sector exportador en el total de ingresos, $\left(X, Y_{1}\right)$, del servicio de la deuda externa, $\left(A_{1}\right)$, y de la tasa de Interés real de Estados Unidos, REU,

\section{Le Inversión}

Para el caso de la inversión, tenemos que el modelo de las dos brechas nos dice que depende en gran parte de la cantidad de ahorros disponibles para tinanciarla. Asl tenemos que, las dos fuentes principales de financiamiento de la inversión provienen del ahorro nacional y del ahorro externo. Desde este punto de vista, ante cualquier limitación que exista, tanto para el ahorro nacional como para el ahorro externo, las posibilidades de acumulación de la economía se verán disminuidas. De esta forma nuestra función inversión parte de la identidad:

$$
I_{1}=S_{1}+F_{1}
$$

donde, $I_{1}$ es la Inversión, $S_{1}$ es el ahorro nacional, y $F_{1}$ es el ahorro externo. Ahora bien, esta identidad convertirla nuestro modelo no lineal en las variables, lo cual dificultarla la estimación. Pero, siguiendo un procedimiento usual, ${ }^{\circ}$ cuando se trabaja con modelos simultáneos las Indentidades se pueden convertir a logaritmos de la siguiente forma:

$$
\ln \left(I_{1}\right)=g_{0}+g_{1} \ln \left(S_{1}\right)+g_{2} \ln \left(F_{1}\right)
$$

Donde, la inversión real, $I_{1}$, es función del ahorro nacional real, $S_{t}, y$ del ahorro externo real, $F_{i}$.

\section{Les Importaclones}

Tal y como vimos antes, en un pais dependiente y con un aparato productlvo trunco como el nuestro, donde los sectores productores de blenes de capital y de insumos necesarios para la industrias están poco desarrollados, la producción tiene un alto componente importado, por lo cual resulta bastante dificil, sino imposible, reducir las importaciones. De esto, se esperarla que la elasticidad ingreso de las importaciones sea bastante atta en nuestro pals. Lo que, de acuerdo al modelo keynesiano que presentamos en el primer capitulo, se convierte en uno de los principales factores determinantes del crecimiento económi$\infty$. 
Por otra parte, tal y como lo senala la teoría de la CEPAL y Kalecki, cuando el crecimiento del sector productor de granos básicos se rezaga respecto al crecimiento de otros sectores, la economía tiende a elevar sus importaciones de granos básicos o de lo contrario habrá mayor inflación. ${ }^{10}$ De esta manera, cuando por alguna razón, que puede ser climatólogica o institucional, el sector productor de granos básicos no logra abastecer la demanda de dichos bienes, entonces las autoridades recurren a la importación para evitar que el precio suba demasiado.

Por otra lado, como lo planteamos en el modelos keynesiano, las importaciones son función de la relación de precios de intercambio entre un pals y sus principales socios comerciales. Sin embargo, en nuestro pals resulta bastante dificil encontrar una serie de tiempo lo suficlenternente larga para una variable, como son los términos de intercambio. Por esto incluimos en nuestra función de importaciones el tipo de cambio efectivo real, que nos relaciona el tipo de cambio y el índice de precios nacional, con una canasta de tipos de cambio e índices de precios de los principales socios comerciales del país en cuestión; para nuestro caso lo calculamos con los cinco principales socios comerciales de El Salvador, Estados Unidos, Alemania, Japón, Guatemala y Costa Rica. Esto nos permitirá observar que tan sensibles son nuestras importaciones a las variaciones entre los precios nacionales y los precios de los principales socios comerciales, teniendo en cuenta los tipos de cambio vigentes en los diferentes paises.

De acuerdo a lo anterior, la especificación de la función de importaoiones es la siguiente:

$$
\ln \left(M_{1}\right)=b_{0}+b_{1} \ln \left(Y_{1}\right)-b_{2} \ln \left(Y G B_{1} Y_{1}\right)-b_{3} \ln \left(T C E R M_{1}\right)
$$

donde $M_{1}$ las importaciones reales, son función del ingreso nacional real, $Y_{1}$, del tipo de cambio efectivo real ponderado con las importaciones," TCERM ${ }_{1}$ y de la participación de la producción de granos básicos en términos reales en la producción real, YGB,Y. El hecho de que la última variable se presente como una proporción del producto nacional, se debe únicamente para evitar un problema de multicolinealidad, pues la producción nacional puede estar correlacionada con la producción de granos básicos.

\section{Las exportaclones}

En un país como el nuestro, donde la participación de las exportaciones de café sobre el total de exportaciones representa alrededor del cincuenta por ciento durante casi todos los anos de las tres últimas dé- 
cadas, es de esperarse que las exportaciones dependan estrechamente del volumen de la producción en el sector productor de este tipo de bienes. Por el mismo motivo, es de esperarse que las exportaciones dependan en gran parte del precio del principal producto de exportación, y de los acuerdos internacionales en el mercado de café concertados en el seno de la OIC.

Por otra parte, el resto de exportaciones, principalmente las exportaciones de bienes manufacturados, dependen en gran parte de la demanda externa, y de la capacidad de nuestros exportadores paira poder aprovechar de forma competitiva los incrementos de la demanda internacional. Desde este punto de vista, dadas los estrechos vínculos comerciales entre los paises centroamericanos, es de esperarse que la demanda de exportaciones salvadorenas experimente un aumento, ante los incrementos en el ingreso de los palses vecinos. Asl, nosotros supondremos que las exportaciones son función del crecimiento del ingreso de los dos principales socios comerciales de Centroamérica con El Salvador: Guatemala y Costa Rica.

Finalmente, las exportaciones también son función de la relación de precios de intercambio, por lo cual, al igual que en el caso de las importaciones, introducimos en la función exportaciones el tipo de cambio efectivo real.

Suponemos que las exportaciones tienen la siguiente relación de comportamiento:

$$
\begin{aligned}
\ln \left(X_{1}\right)= & d_{0}+d_{1} \ln \left(Y C_{1}\right)+d_{2} \ln \left(P C_{1}\right)+d_{3} \ln \left(Y I_{1}\right)+\ldots \\
& \ldots+d_{4} \ln \left(T C E R X_{1}\right)
\end{aligned}
$$

donde las exportaciones, $X_{1}$, son función de la producción del sector cafetalero, $Y C_{1}$, de los precios mundiales del café, $P C_{1}$, del nivel de ingreso de los principales socios comerciales centroamericanos de nuestro pals, $Y_{y}$, y del tipo de cambio efectivo real ponderado con las exportaciones, TCERX, ${ }^{12}$

\section{La producción}

Por el lado de la producción, tal y como lo sugieren las teorlas del crecimiento económico, ésta es función de la inversión, en la medida que la inversión aumenta, la producción también aumentará.

Pero, una vez que consideramos al sector extemo de la economla, la producción también se vuelve función de la disponibilidad de divisas. Pues, en un país cuya producción es sumamente dependiente de insu- 
mos importados, tenemos que para que ésta aumente se requerirán de mayores cantidades de divisas, de tal forma que la escasez de éstas se puede convertir en un cuello de botella para el crecimiento. En este sentido, para cualquier pais una de las principales fuentes de divisas son las exportaciones mismas, por esto nosotros suponemos que las exportaciones juegan un papel importante como factor del crecimiento económico. Además, tal como lo senalan los enfoques keynesiano y de las dos brechas, hay bastantes razones para suponer esta relación. Entre ellas, el papel que juega la demanda externa en el crecimiento económico y el empeoramiento o la mejoría en la relación de precios de intercambio.

Por otra parte, en nuestro pais es bastante conocido que el capital de trabajo de las empresas es muy dependiente del crédito interno disponible en la economia, dado el escaso desarrollo de los mercados de capitales al interior del pais. De esto último se deriva que el crecimiento económico responde a variables monetarias, ${ }^{13}$ y en este sentido es de esperarse que incrementos en el crédito interno favorezcan el crecimiento económico a través de dos vias, el aumento en la demanda interna y la agilización en el proceso de producción. Sin embargo, este tipo de relación se da con cierto rezago, de tal manera que se espera que un incremento en el crédito interno en un periodo, tenga su efecto positivo sobre el crecimiento económico en el siguiente.

Por tanto, por el lado de la producción tenemos la siguiente función de comportamiento:

$$
\ln \left(Y_{1}\right)=k_{0}+k_{1} \ln \left(I_{1}\right)+k_{2} \ln \left(X_{1}\right)+k_{3} \ln \left(C_{1}-1 / Y_{1}\right)
$$

Donde $Y_{1}, I_{1}$ y $X_{1}$ se definen igual que antes, y $\mathrm{Cl}_{1}-1$, es el crédito interno con un periodo de rezago, y lo dividimos entre el nivel de producción para evitar la multicolinealidad con la inversión, ya que entre estas dos variables es de esperarse que exista cierta correlación. En esta función de producción se observa, que cuando aumenta la inversión aumentará la producción. También, aunque no de manera directa, si hay un incremento en los precios del café, nosotros sabemos, por la función de exportaciones, que habrá un incremento de éstas, teniendo un efecto favorable sobre el crecimiento económico. Por otra parte si hay un aumento de las importaciones las necesidades de capital extranjero aumentarán, de tal manera que si éstas son satisfechas, habrá más fondos para financiar la inversión, lo cual tendrá un efecto positivo sobre el crecimiento. 


\section{Los flujos de capltal extranjero}

Finalmente, para cerrar el modelo, supondremos que los flujos de capital extranjero son función de las exportaciones y de las importaciones. De esta forma, cuando haya un aumento de las exportaciones, las necesidades de capital extranjero serán menores; caso contrario cuando experimentemos una reducción de éstas. En cuanto a las importaciones, si aumentan, habrá mayor necesidad de financiamiento externo. y si se reducen las necesidades serán menores. Esta es la razón por la cual nosotros utilizamos la balanza comercial de bienes y servicios, y no la balanza de cuenta corriente o balanza de pagos, para expresar to que es la brecha comercial. Pues en los otros dos conceptos se incorporan las entradas de capital, en la cuenta comiente se toman en cuenta las donaciones y transferencias, mientras que en la balanza de pagos se consideran también las entradas de capital extranjero en concepto de préstamos privados y públicos, a corto y a largo plazo. ${ }^{14}$ Por tanto, los niveles de flujos netos de capital extranjero quedan representados por la identidad:

$$
F_{1}=M_{1}-X_{1}
$$

Asi, tenemos que la función de flujos de capital extranjero, por ser una identidad, queda especificada de una forma similar a la inversión, de la siguiente forma:

$$
\ln \left(F_{1}\right)=c_{0}+c_{1} \ln \left(M_{1}\right)-C_{2} \ln \left(X_{1}\right)
$$

Donde, todas las variables se definen igual que antes.

\section{Una visión del modelo en su conjunto}

A continuación, mostramos el modelo como un todo en la TABLA No. 2.1, y explicamos como funciona ante las variaciones de los diferentes determinantes del crecimiento económico.

Por ejemplo, qué sucedería en la economia si hubiera un incremento en la demanda externa, que se manifestaria en el crecimiento de la producción de los principales socios comerciales del pais. En un primer momento, aumentarian las exportaciones en la ecuación (4), luego esto tendría como consecuencia una mayor disponibilidad de divisas permitiendo que la producción aumente, de manera que reduce el estrangulamiento al crecimiento económico. Pero, a la vez habria un incremento en el ahorro nacional, lo cual permitiria un mayor nivel de inversiones (ecuación 2), favoreciendo asi el crecimiento económico (ecuación 5). Y 
finalmente, el incremento en el crecimiento económico demandaría un nivel mayor de importaciones (ecuación 3), por lo cual tendria que aumentar el flujo de capital extranjero (ecuación 6), dependiendo del hecho de si las exportaciones han crecido o no lo suficiente para cubrir las necesidades de divisas.

También es interesante ver el papel que juega el ahorro externo en el crecimiento económico dentro del contexto del modelo. Tal como vimos en el capítulo anterior, tanto para el modelo de las dos brechas como para el modelo de crecimiento con restricción externa basado en un enfoque keynesiano, ésta variable juega un papel importante en el crecimiento de la economia. Sin embargo dichos enfoques, por tratar de destacar la relevancia de este punto, descuidan un poco los mecanismos a través de los cuáles el ahorro externo incide sobre el crecimiento, planteando sus funciones de crecimiento económico a partir de la forma reducida de sus modelos, y dejando de lado la forma estructural donde se plantean las funciones de comportamiento. ${ }^{15}$ En nuestro caso, es por esto que no aparece el ahorro externo como un determinante directo del crecimiento económico (ecuación 5), sino que indirectamente a través del financiamiento de la inversión (ecuación 2).

Por ejemplo, supongamos un incremento en las inversiones autónomas, esto implicaria un aumento en los niveles de crecimiento económico, aumentando los ingresos nacionales (ecuación 5), este incremento provocaría dos efectos: elevarla los niveles de ahorro nacional al aumentar los ingresos del sector no exportador (ecuación 1); y también elevaria los niveles de importación por los requerimientos que surgen del crecimiento económico (ecuación 3), aumentando los niveles de requerimiento de flujos de ahorro externo (ecuación 6). Pudiéndose ver que la inversión a generado su propio ahorro, como en los modelos keynesianos (ecuación 2), a través del aumento del ahorro nacional, aunque levemente porque hemos supuestos que los ahorros son menos sensibles a estos ingresos; y del aumento o agravamiento de la brecha comercial. Sugiriendo que el ahorro externo no entra a la economía solamente con el propósito de financiar el desarrollo económico ampliando los recursos financieros para la inversión (ecuación 2), sino que también para eludir un problema inherente a la estructura de nuestro aparato productivo, que resulta del comportamiento asimétrico de las importaciones y las exportaciones, donde las primeras son sumamente dependientes de los niveles de producción intema y de la producción de granos básicos (ecuación 3), y las segundas son más influenciadas por variables externas (ecuación 4). 
TABLA No. 2.1

EL MODELO DE CRECIMIENTO ECONOMICO

CON RESTRICCION EXTERNA

$$
\begin{aligned}
& \ln \left(S_{1}\right)=e_{0}+e_{1} \ln \left(Y_{1}-X_{1}\right)+e_{2} \ln \left(X_{1} Y_{1}\right)-e_{3} \ln \left(A_{1}\right)-a_{4}(\text { REUt }) \\
& \ln \left(I_{1}\right)=g_{0}+g_{1} \ln \left(S_{1}\right)+g_{2} \ln \left(F_{1}\right) \\
& \ln \left(M_{1}\right)=b_{0}+b_{1} \ln \left(Y_{1}\right)+b_{2} \ln \left(Y G B_{1} Y_{1}\right)+b_{3} \ln \left(T C E R M_{1}\right) \\
& \ln \left(X_{1}\right)=d_{0}+d_{1} \ln \left(Y C_{1}\right)+d_{2} \ln \left(P C_{1}\right)+d_{3} \ln \left(Y_{1}\right)+d 4 \ln \left(T C E R X_{1}\right) \\
& \ln \left(Y_{1}\right)=k_{0}+k_{1} \ln \left(I_{1}\right)+k_{2} \ln \left(X_{1}\right)+k_{3} \ln \left(C_{1}-1\right) \\
& \ln \left(F_{1}\right)=c_{0}+c_{1} \ln \left(M_{1}\right)-c_{2} \ln \left(X_{1}\right)
\end{aligned}
$$

varlables endogenas:

$S$ : ahorro nacional real

I : inversión interna bruta real

$M$ : importaciones reales de bienes y servicios

$X$ : exportaciones reales de bienes y servicios

$Y$ : producto interno bruto real

$F$ : ahorro externo real

\section{varlables exógenas:}

A : servicio de la deuda externa

REU : tasa de interés real de Estados Unidos

YGB : producción real granos básicos

TCERM : tipo de cambio efectivo real ponderado con importaciones

TCERX : tipo de cambio efectivo real ponderado con exportaciones

YC : producción real de café

PC : precios fob mundiales del café lavado

YI : ingreso real de los principales socios comerciales de El Salvador. 


\section{Estimación del modelo y exposición de los resultados}

En el presente capítulo explicamos cuáles fueron los procedimientos para la estimación del modelo y qué método ocupamos. Posteriormente, exponemos los resultados, y hacemos el análisis estadistico y económico de los mismos, trantando de ver a lo largo del periodo en estudio los impactos de las diferentes variables. Finalmente, hacemos un recuento histórico para ver cuál es la relación de las variables fundamentales a to largo del periodo en estudio.

\section{A. Estimaclón del modelo}

Dado el carácter simultáneo del modelo, la utilización de mínimos cuadrados ordinarios para su estimación no seria adecuada, pues resulta que de seguirse este método los parámetros tendrian un sesgo. Por to tanto, debemos aplicar un método que considere la simultaneidad de las ecuaciones. Para esto existen varios métodos, de los cuales seleccionamos el de minimos cuadrados en dos etapas. ${ }^{16}$

Además, a la hora de correr el modelo incluimos una variable ficticia en cada una de las ecuaciones para tomar en cuenta los efectos que tiene sobre la economia la grave situación político-militar que enfrenta el pais. Y también, por dificultades fuera de nuestro alcance, fue imposible encontrar una serie de datos sobre el servicio de la deuda externa, por to cual excluimos esta variable del modelo.

Teniendo en cuenta estas consideraciones, en la Tabla No. 2 presentamos los resultados obtenidos de la aplicación del método de mínimos cuadrados en dos etapas a nuestro modelo, para la economia salvadorena, abarcando el periodo de 1962 a 1988.

A nivel general se observa que todas las ecuaciones, con excepción de la (2), tienen un estadistico durbin-watson, D.W., que me indica que caen en la zona de indefinición de manera que no podemos saber si existe o no autocorrelación. En cuanto a la ecuación (2), que corresponde al crecimiento de la inversión, tenemos que no presenta el problema de correlación serial, de acuerdo al mismo estadistico.

Además, los signos de los coeficientes estimados en todas las ecuaciones del modelo fueron los correctos, con excepción de la variable ficticia para algunas de las ecuaciones; es decir, que van de acuerdo a lo planteado por la teoria.

En cuanto al coeficiente de correlación, en general, es alto, ya que el menor es de 0.62, para la ecuación del ahorro, mientras que el máximo se dió en la función de producción, donde dicho coeficiente es de 0.93; 10 cual significa que las variables independientes que con- 
forman esta ecuación explican las variaciones de la producción en un $93 \%$, lo que permite decir que la bondad del ajuste es bastante alta. ${ }^{17}$

Por otra parte, el estadístico $F$, resultó significativo al nivel del $1 \%$ para todas las ecuaciones, lo cual indica que en su conjunto los parámetros estimados en cada una de las ecuaciones del modelo son diferentes de cero.

Comenzando por el análisis particular de cada ecuación, tenemos que la significancia de los parámetros de la ecuación del ahorro, tenemos que el correspondiente al ingreso del sector no exportador no es significativo, aunque su signo si es correcto, mientras que los que se refieren a los ingresos del sector exportador y a la tasa de interés real de Estados Unidos son significativos al nivel del $1 \%$.

Desde el punto de vista económico, tenemos resultados bastante interesantes, como el hecho de que la elasticidad ahorro de los ingresos del sector no exportador, 0.058 , es menor que la elasticidad ahorro de los ingresos del sector exportador, $1.055,{ }^{10}$ lo cual corrobora las hipotesis de Maiselz (1968), Lee (1971) y Laumas (1982), de que los ingresos en este sector son más concentrados, ${ }^{19}$ o se acaparan en un grupo minoritario y que también existe la posibilidad de que el ahorro nacional se pueda ver favorecido dado que son ingresos más facilmente tributables, influenciando con mayor fuerza los cambios en el ahorro nacional, además del incremento del ingreso que resulta del efecto demanda de las exportaciones, siendo éste uno de los principales mecanismos a través del cual el sector externo se convierte en un determinante fundamental para nuestra economia. Además, según lo planteado por el modelo de las dos brechas, de acuerdo a Chenery y Eckstein (1970), cuando la brecha del comercio es dominante, las divisas son un factor escaso, y dado que la inversión depende mucho de la capacidad de importaciones, en la medida que crezcan las exportaciones, por el incremento de las divisas habrá mayores oportunidades de inversión, con lo cual parte del ahorro nacional ex-ante, que no se podia realizar, en este caso si podria. Esto es, por tanto, una evidencia empirica de que en nuestro pais la brecha externa es dominante, y que por tanto existen ahorros deseados, o ex-ante que no llegan a realizarse, por la falta de oportunidades de inversión ante la escasez de divisas. ${ }^{20}$

En cuanto a la tasa de interés real de Estados Unidos, vemos que ésta afecta negativamente el ahorro nacional, de manera que un incremento en un punto porcentual de ésta, ceteris paribus, puede reducir nuestros ahorros en casi 0.11 por ciento, cifra que si bien no es muy alta, sl muestra que hay alguna influencia, sobre todo porque los mayores rendimientos del dinero en el exterior puede estimular a las 
TABLA NO. 2

RESULTADOS OBTENIDOS MEDIANTE LA ESTIMACION DEL MODELO POR EL METODO DE MINIMOS CUADRADOS EN DOS ETAPAS

\begin{tabular}{|c|c|c|}
\hline \multicolumn{2}{|c|}{ 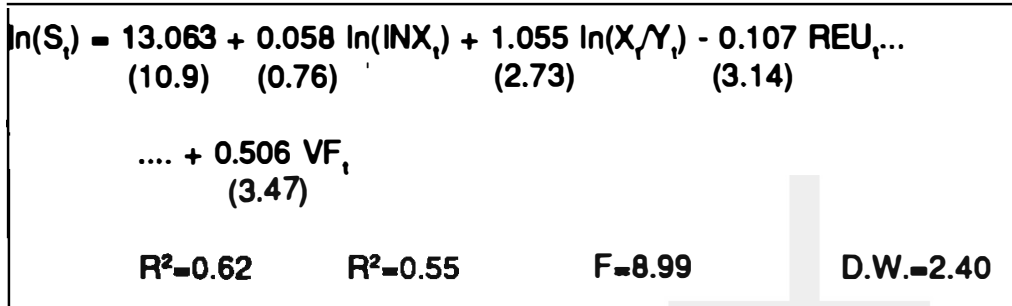 } & (1) \\
\hline 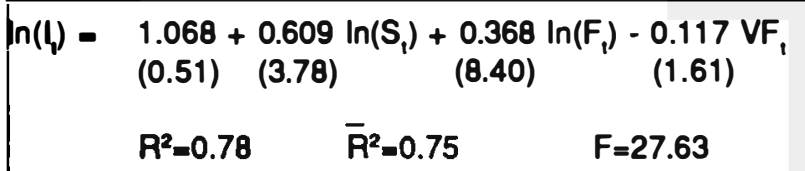 & D.W. $=1.77$ & (2) \\
\hline 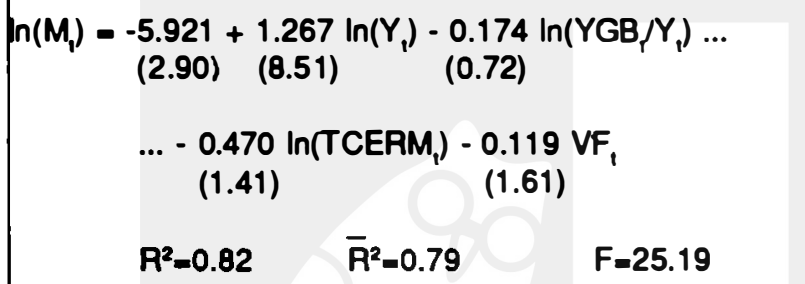 & D.W. $=1.41$ & (3) \\
\hline 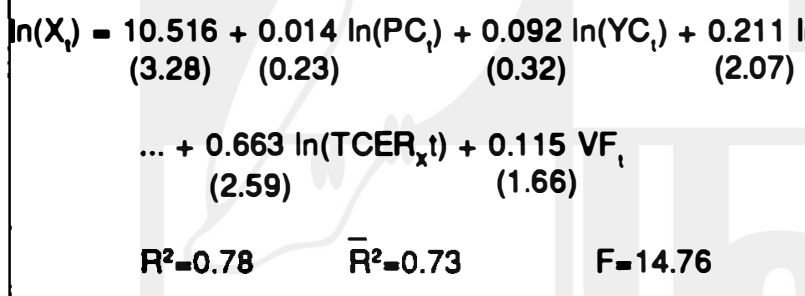 & D.W. $=1.48$ & (4) \\
\hline $\begin{array}{c}\ln \left(Y_{1}\right)=\underset{(4.65) \quad(5.98)}{6.005}+0.416 \ln \left(I_{1}\right)+\underset{(2.05)}{0.278} \ln \left(X_{1}\right)+\underset{(2.31)}{0.207} \ln \left(C_{1}-\right. \\
\ldots+0.024 V_{1} \\
(0.45)\end{array}$ & D.W. $=1.17$ & (5) \\
\hline 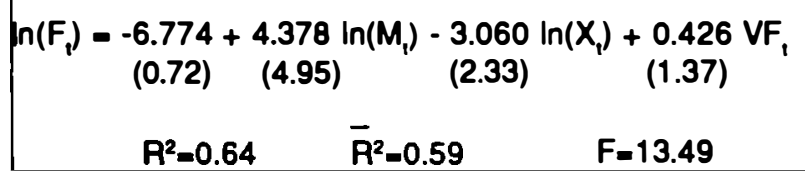 & D.W. $=1.18$ & (6) \\
\hline
\end{tabular}

Nota: Los coeficientes entre paréntesis son los estadísticos $t$. 


\section{GRAFICO 1 \\ IMPACTOS ESTIMADOS SOBRE LA TASA DE \\ CRECIMIENTO DEL AHORRO 1963-1988}

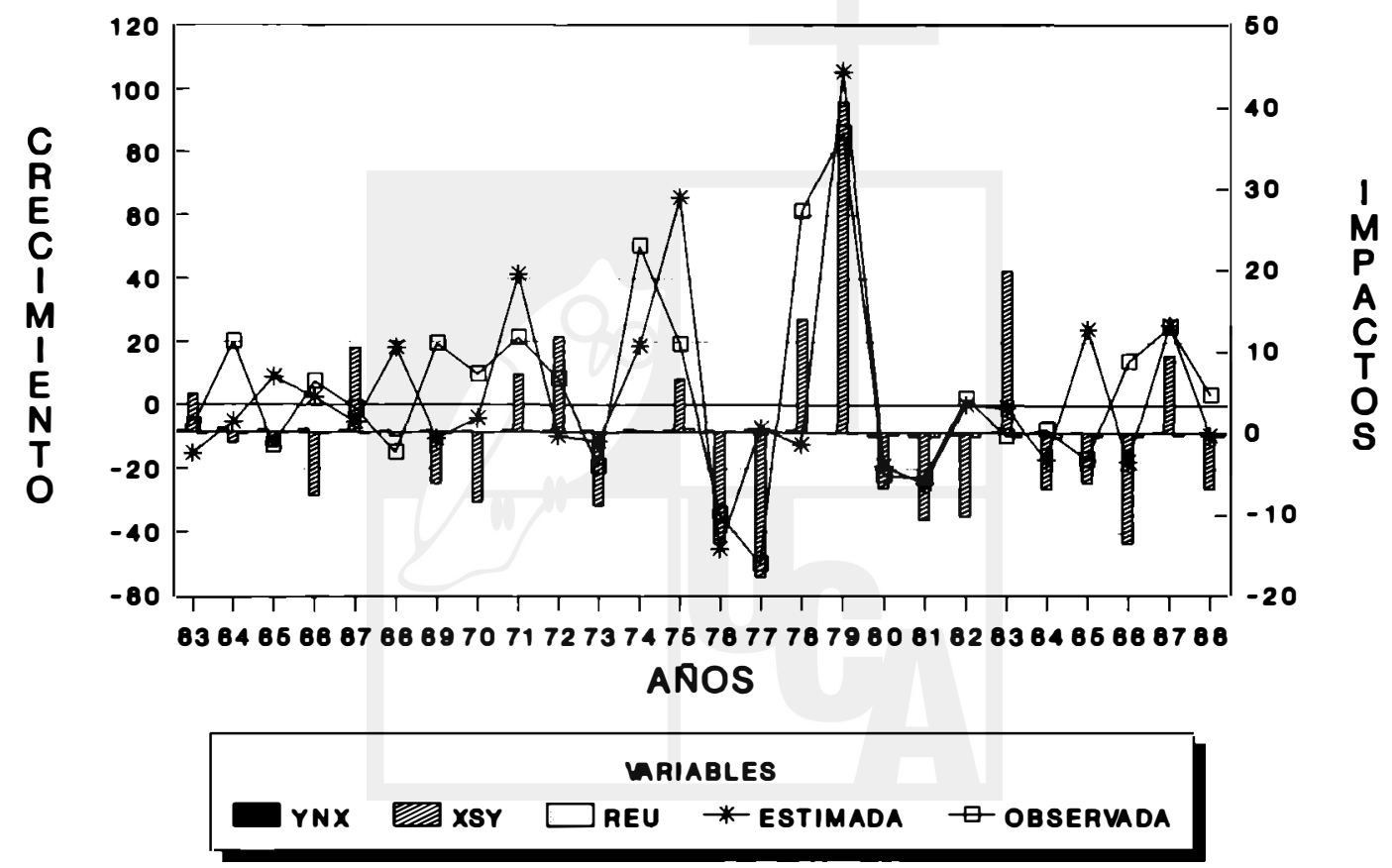


empresas extranjeras a sacar sus ganancias en mayores cantidades para colocarlos en los bancos de Estados Unidos, experimentándose asi una salida de recursos nacionales que reducen los ingresos netos de factores del exterior, dejando un PNB menor y por lo tanto los niveles de ahorro serian menores. ${ }^{21}$

En cuanto a la variable ficticia, tenemos que el signo es contrario a to esperado, ya que se supone que en el periodo de crisis por la caida del ingreso y por la fuga de capitales, el ahorro nacional podria disminuir. Sin embargo, el signo positivo de esta variable en la ecuación. está indicando un incremento en el intercepto de la ecuación del ahorro, lo que se podria explicar por el hecho de que en la década de los ochenta se ha experimentado, con los programas de estabilización y ajuste, un efecto regresivo en la distribución del ingreso, to que trae como consecuencia posibles incrementos en el ahorro.

También, multiplicando las elasticidades obtenidas por la tasa de crecimiento de sus correspondientes variables explicativas, en la ecuación, podemos obtener los impactos que cada una de éstas variables ejercen sobre la tasa de crecimiento del ahorro. De acuerdo a las estimaciones, podemos ver en las tendencias que presenta el gráfico 1 , que para la función ahorro intemo, S, a lo largo de todo el periodo en estudio, la variable que ha jugado un papel importante sobre las variaciones que presenta éste, son los ingresos del sector exportador, XSY. ${ }^{22}$ Así, cuando se comparan los resultados, este sector tiene los mayores niveles de influencia sobre esta variable, en cualquiera de los anos, mientras que la influencia de la tasa de interés de EE.UU., REU, y la de los ingresos del sector no exportador no han sido muy determinantes.

Es importarıe mencionar que cuando se hace el análisis de la variable observada y de la estimada podemos ver que el modelo reproduce el comportamiento de la variable, es decir, los datos observados y los estimados no presentan mayores diferencias, tanto en los periodos en que el ahorro ha tendido a elevarse como a decrecer, lo cual nos refleja una buena aproximación a la realidad.

En cuanto a la ecuación de la inversión, tanto el parámetro correspondiente al ahorro nacional como el que acompana al ahorro externo son significativos al nivel del $1 \%$. Aunque para la inversión, estos resultados eran esperados, debido a que dicha ecuación se deriva de una identidad, desde el punto de vista económico se observa que la elasticidad ahorro nacional de la inversión, 0.609 , es mayor que la elasticidad ahorro externo de la misma variable, 0.368 , lo cual nos indica que en nuestro pais la inversión es más sensible a los cambios en el ahorro 


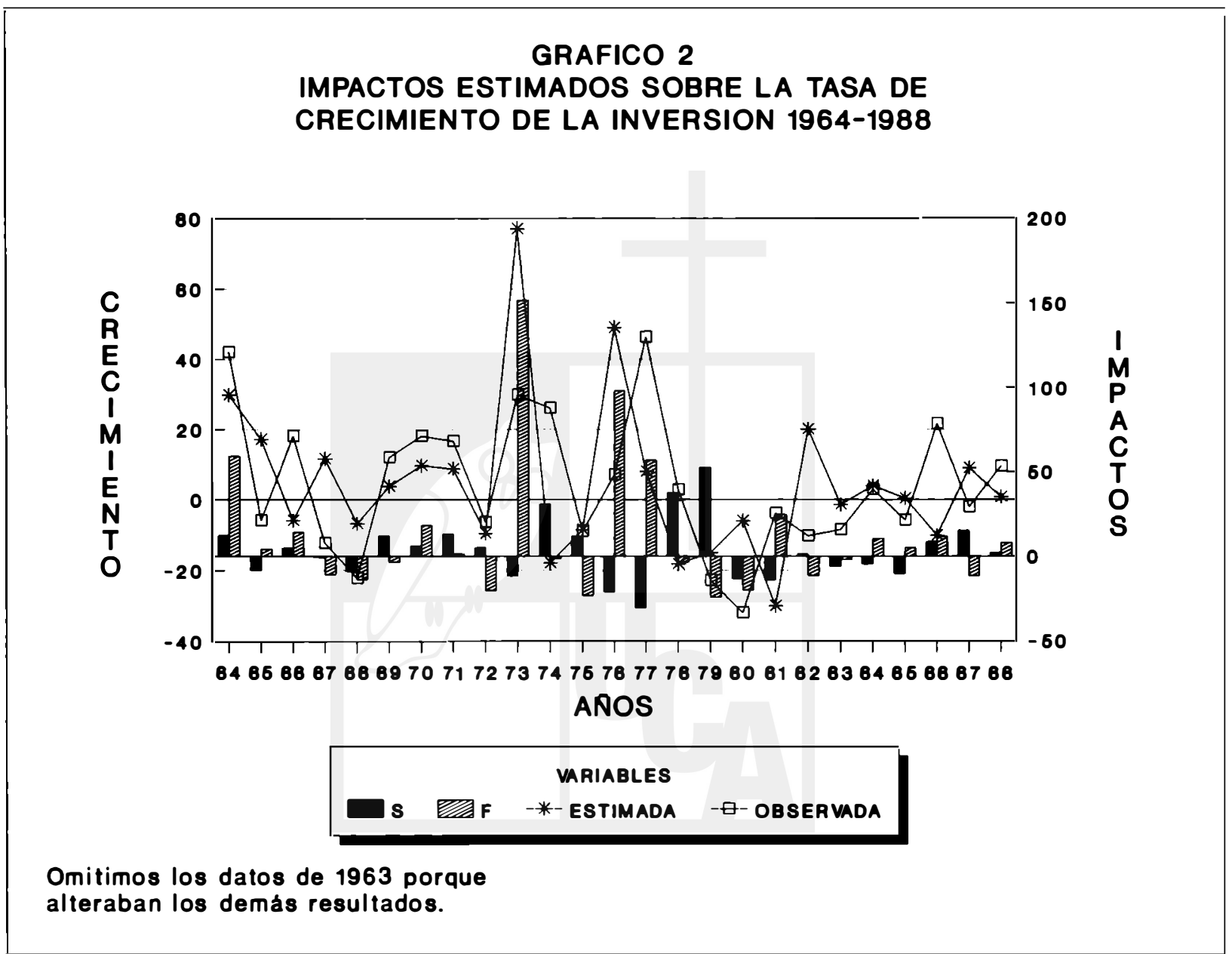

Digitalizado por Biblioteca "P. Florentino Idoate, S.J."

Universidad Centroamericana José Simeón Cañas 
nacional que a los cambios en el ahorro externo, lo cual se puede explicar a partir del hecho de que el ahorro nacional, en las cuentas nacionales se calcula a partir de la identidad donde la inversión es igual al ahorro nacional más el ahorro externo, una vez conocida la inversión y el ahorro externo, el ahorro nacional se obtiene por diferencia. Sin embargo, esta forma de calcular el ahorro tiene sus deficiencias, pues no todo el ahorro externo se convierte en inversión al interior del pais, parte se destina al consumo directo y a la compra de material bélico. ${ }^{23}$ Lo cual puede explicar el hecho de que aún cuando la brecha externa sea dominante, la elasticidad ahorro externo de la inversión es menor, en el sentido de que el ahorro externo no se destina plenamente a los gastos de inversión.

Desde el punto de vista de la variable ficticia, tenemos que el signo es correcto, pero dado que la ecuación se deriva de una identidad no se pueden derivar conclusiones en cuanto al efecto de la crisis sobre la inversión nacional. Aunque es obvio que ésta haya sido negativa.

Viendo directamente los impactos estimados que se derivan de la ecuación de la inversión en el gráfico 2 , se puede decir que tanto en la primera década como en la tercera, el modelo permite analizar a dicha variable sin mayores diferencias entre los datos observados y estimados. Aunque en la década de los setenta hay ciertas divergencias entre el comportamiento de la tasa de crecimiento observada y la estimada, tal vez por las distorsiones del incremento en los precios del petróleo, sobre todo en 1973, y el desequilibrio que implicó la inflación mundial en nuestra balanza de bienes y servicios.

En cuanto a la variable que influye más en el comportamiento de la tasa de crecimiento de la inversión a lo largo del periodo en estudio, se puede ver que en general es la tasa de crecimiento del ahorro externo, debido a que éste fluctúa más que la tasa de crecimiento del ahorro nacional, y a qué en nuestro caso la brecha externa es dominante, tal como lo demuestran los resultados de la ecuación anterior, lo cual sugeriria que cuando haya incrementos en el ahorro externo, las oportunidades de inversión se van a ver alteradas por el mayor acceso a las divisas, indicándonos uno de los mecanismos a través de los cuales el entorno internacional hace fluctuar la inversión nacional, y por tanto, también la tasa de crecimiento de la producción. Esto se da a pesar de que la elasticidad ahorro nacional de la inversión es mayor que la elasticidad ahorro externo de la misma.

En cuanto a la ecuación de las importaciones, respecto a la significancia de los parámetros, tenemos que los correspondientes a la producción de granos básicos, a la variable ficticia y al del tipo de cambio 
efectivo real no son significativos, y el del ingreso nacional si lo es al $1 \%$, aunque los signos de todos los parámetros si son correctos.

Con esto, nosotros podemos confirmar que la variable que más influencia a las importaciones es la producción nacional, asi, una variaclón en uno por ciento de esta última variable provoca un incremento de $1.27 \%$ en las importaciones, si los demás factores permanecen constantes. Lo cual nos indica que la elasticidad ingreso de las importaciones es bastante alta, como resultado de la extrema dependencia de nuestra economía respecto a la importación de insumos y de bienes de capital (carácter trunco) para sostener o incrementar los niveles de producción, y de los patrones de consumo que adoptan sectores de la población salvadoreña, resultado de la elevada concentración del ingreso nacional, tal como to señalan los enfoques del modelo de las dos brechas y el estructuralista de la CEPAL; viniendo a ejercer todo esto una presión sobre las necesidades de financiamiento externo, exigiendo que la economia recurra a éste en mayores cantidades para poder sostener los niveles de inversión y crecimiento; además del hecho de que las exportaciones no logran incrementarse fácilmente ante los aumentos de la producción nacional, que tienen muy poco o nada que ver en el volumen y el valor de éstas.

Por otra parte, aunque el coeficiente de la producción de granos básicos no es significativo, el signo sugiere que cuando hay incrementos en la producción de granos básicos el país no necesita incurrir en mayores importaciones, mientras que cuando, por cualquier razón (una sequia, una inundación, etc.), exista una reducción en la producción de granos básicos el país se verá obligado a importarlos, compitiendo con los otros tipos de importaciones por las divisas disponibles en la economia, tal como to plantean el enfoque estructuralista y los aportes de Kalecki. Asi tenemos que, por ejemplo, en los últimos tres anos de sequia que experimentó el pais, 1985, 1986 y 1987, el impacto estimado sobre la tasa de crecimiento de las importaciones fue positivo, lo cual muestra cierta evidencia al respecto. Esto es importante desde el punto de vista de los factores externos determinantes del crecimiento economico, dado que el rezago en la producción de granos básicos es un elemento que exige incrementar los niveles de importación para satisfacer las necesidades de consumo inmediatas, lo que aunado a las necesidades apremiantes de divisas que resultan del aparato productivo trunco, viene a agravar más la situación, pues las importaciones de granos básicos, compiten en la utilización de las escasas divisas, con las importaciones de insumos y de bienes de capital, que son más importantes para el sostenimiento del crecimiento económico, planteandose aqui el problema de la utilización de las divisas para el consumo 
presente, o para el crecimiento económico, que supuestamente garantizarla el consumo en el futuro. ${ }^{24}$

Además, dado que el coeficiente del tipo de cambio efectivo real de las importaciones no es significativo, se puede confirmar que las variaciones de precios relativos entre nuestro pais y los principales socios comerciales, junto con las relaciones de tipo de cambio, no ejercen una influencia importante sobre los niveles de nuestras importaciones, 10 que nos lleva a reforzar la idea de que en nuestro pais las importaciones están determinadas fundamentalmente por las otras dos variables, crecimiento de la producción nacional y crecimiento del sector productor de granos básicos, debido a las características estructurales de nuestra economia.

Por el lado de las exportaciones el tipo de cambio efectivo real resultó significativo a un nivel del $2 \%$, indicando que un incremento del $1 \%$ en el tipo de cambio efectivo real, manteniendose los demás factores constantes, provocará un aumento en nuestras exportaciones del $0.663 \%$. En concordancia con los planteamientos teóricos que sostienen que si por ejemplo el tipo de cambio nominal se mantiene constante. política de tipo de cambio tijo, y a la vez el incremento de lo precios nacionales es menor que el incremento en los precios de los principales socios comerciales, habrá un cambio favorable en la competitividad internacional de nuestros bienes, lo que se traducirá en un aumento de nuestras exportaciones, tal como lo sefiala el mismo modelo de Thirlwall y Hussain. Por ejemplo, en la década de los ochenta la inflación en El Salvador tue mayor que la de los principales socios comerciales, y hasta antes de 1985, el tipo de cambio nominal se mantuvo constante, 10 que se manifestó en una pérdida de competitividad de nuestros productos, y por tanto, en una reducción en el volumen de nuestras exportaciones.

Comparando este resultado con el de las importaciones tenemos que las exportaciones son más sensibles a las variaciones en el tipo de cambio efectivo real que las importaciones, básicamente por dos razones. En primer lugar, las importaciones son menos sensibles a las variaciones en la relación de intercambio, por el carácter de éstas, que responden más a las necesidades de bienes intermedios y de capital, que son indispensables para el funcionamiento de nuestra economía independientemente de los niveles de precios, al rezago en la producción de alimentos agrícolas, y a los patrones de consumo de ciertos sectores de la población. Y en segundo lugar, por el carácter homógeneo de algunas de nuestras exportaciones, tales como el café, el azúcar y el algodón, en cuyos mercados la calidad de nuestros productos es 


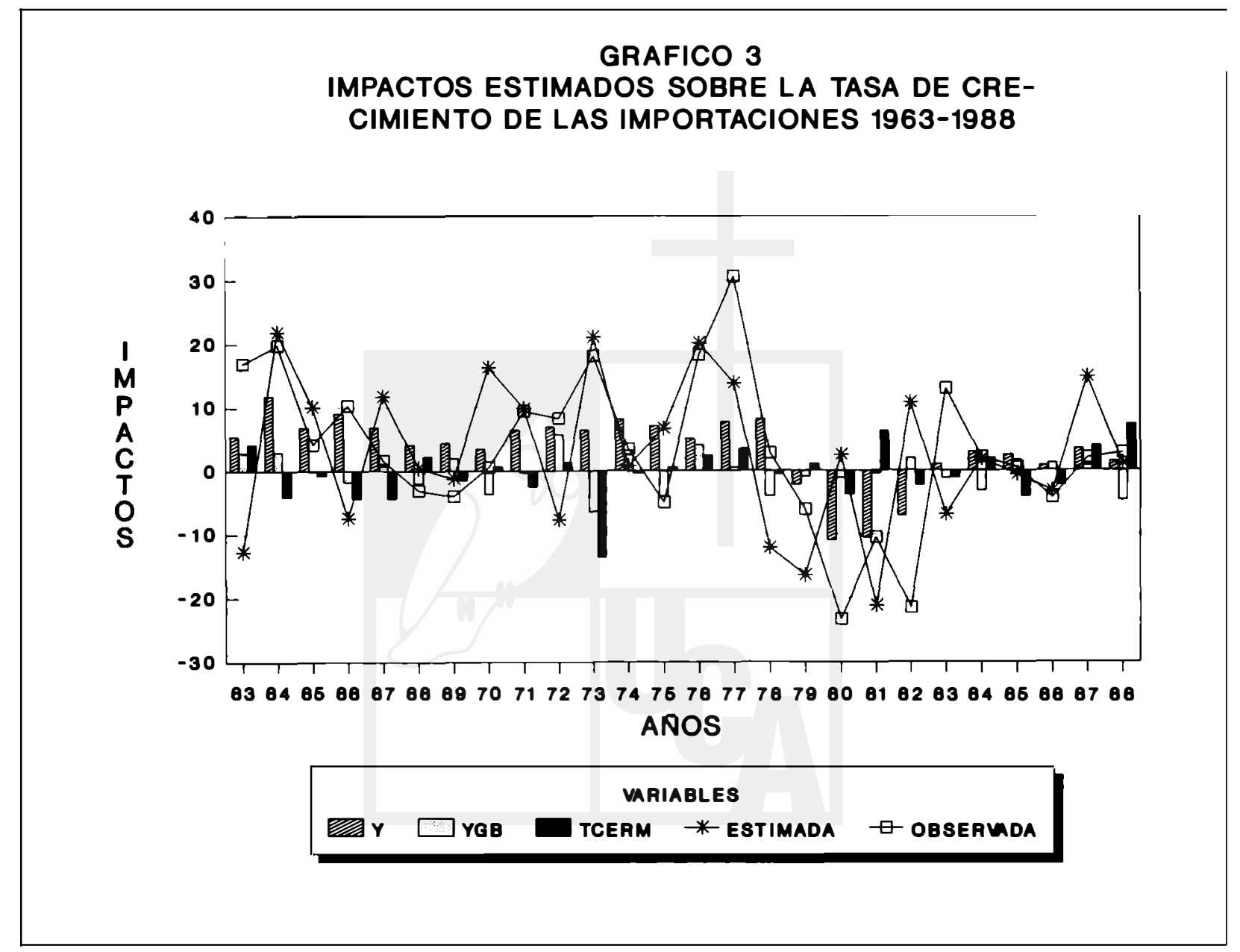

Digitalizado por Biblioteca "P. Florentino Idoate, S.J."

Universidad Centroamericana José Simeón Cañas 
semejante a la de otros países, facilitándose asi la penetración en mercados externos, lo que hace que sean más sensibles a las variaciones en los precios.

Por otra parte, aunque el tipo de cambio efectivo real haya resultado significativo para las exportaciones, no se debe creer que con incrementos del mismo a través de devaluaciones nominales vamos a experimentar incrementos en nuestras exportaciones. Hay otros estudios que senalan que el efecto positivo de la devaluación se ve anulado en un periodo bastante corto, debido a que provoca incrementos en los niveles de precios de nuestro país, por el proceso de formación de los mismos, considerando la alta dependencia de insumos importados de parte de nuestra economia. ${ }^{25}$

En cuanto a la variable ficticia, aunque su coeficiente no es significativo, el signo sugiere que durante el periodo de crisis las dificultades para realizar importaciones se agravaron aún más, por la reducción de los niveles de las exportaciones, por la fuga de capitales y por el decrecimiento de los niveles de ingreso real.

Desde el punto de vista de los impactos estimados sobre el crecimiento de las importaciones, multiplicando siempre las elasticidades estimadas por las tasas de crecimiento observadas de las respectivas variables, en todo el periodo se observa que la mayor influencia proviene de la tasa de crecimiento de la producción y de la producción en el sector productor de granos básicos, lo que se observa en el gráfico 3. Asi tenemos que el crecimiento positivo de la producción durante todos los anos que van de 1963 a 1978, ésta ejerce una influencia positiva sobre la tasa de crecimiento de las importaciones, mientras que en los anos de 1979 a 1982 las importaciones disminuyeron, como resultado de la contracción en la actividad económica, teniendo una leve recuperación en los anos siguientes, lo que es perfectamente consistente con el tamaño de la elasticidad ingreso de las importaciones, y con las necesidades de insumos y bienes de capital importados de nuestro aparato productivo. A su vez, se observa que la producción de granos básicos ejerce su influencia sobre el crecimiento de las importaciones, tal como lo sefalabamos más arriba, ejerciendo una presión bastante fuerte sobre los niveles de importaciones, aunque hay que tener ciertas reservas en cuanto a la precisión de los impactos estimados, debido a que la elasticidad de las importaciones con respecto a la proporción de la producción de granos básicos en el PIB, no resultó ser significativa. También, manteniendo la misma cautela que en la variable anterior, el tipo de cambio efectivo real ponderado con las importaciones, TCERM, se vuelve determinante, únicamente en algunos anos, como por ejem- 
plo en 1973, con el incremento de los precios del petróleo, y los anos de 1985 y 1986, donde existia el proceso de devaluación del colón salvadoreno, primero con un mercado paralelo de divisas, y después con la declaración oficial de la devaluación, el TCERM experimentó un incremento, lo que ejerció una presión hacia la reducción de la tasa de crecimiento de las importaciones, aunque esta presión fue pequena, se superó por el efecto que ejerce el crecimiento de la producción y del sector productor de granos básicos, que como senalamos antes, juegan un papel decisivo en nuestra economía, no logrando corregir el problema del déficit en el sector externo. Si bien es cierto que existe un diferencia entre la variable observada y la estimada, éstas presentan la misma tendencia.

Por otro lado, en la función de exportaciones, los parámetros de la producción de café y de los precios del café no son significativos, por to que las conclusiones que se puedan derivar de ellos se deben de tomar con cierta precaución. ${ }^{26}$ Sin embargo, esta situación se pudo haber dado por el hecho de que tanto la producción en el sector cafetalero como los precios del café, presentan a lo largo del periodo fluctuaciones que son relativamente pequenas (con algunas excepciones para los precios del café), lo que influye negativamente sobre la captaciór. de éstas por parte de las estimaciones econométricas, donde probablemente la relación habria sido mejor captada si todas las fluctuaciones fueran grandes, 10 que no tiene porque restarle importancia a las variables en cuestión.

Teniendo en cuenta esta consideración, los signos sugieren que incrementos en estas variables favorecen el crecimiento de nuestras exportaciones. De tal manera que aumentos en la producción de café se podrian traducir en incrementos en las exportaciones; aunque esto se puede relativizar un poco por el sistema de cuotas en el mercado mundial del całé, manejado por la OIC. Y también, las fluctuaciones en los precios del café podrían afectar el crecimiento de las exportaciones.

En cuanto al coeficiente que acompanan a la demanda extema, representada por el ingreso ponderado de Guatemala y Costa Rica, es significativo al nivel del $5 \% .{ }^{27} \mathrm{Si}$ el PNB ponderado de Guatemala y Costa Rica se incrementa en $1 \%$, nuestras exportaciones aumentarán en $0.211 \%$, si los demás factores se mantienen constantes, 10 cual es una evidencia empírica significativa, que demuestra que los estrechos vínculos comerciales entre la economia salvadorena y la de estos dos paises son un factor determinante para el funcionamiento de nuestra economla, dado que se da un efecto de demanda de nuestras exportaciones ante el incremento del ingreso de estos países, tal como lo se- 


\section{GRAFICO 4}

IMPACTOS ESTIMADOS SOBRE LA TASA DE CRECIMIENTO DE LAS EXPORTACIONES 1963-1988

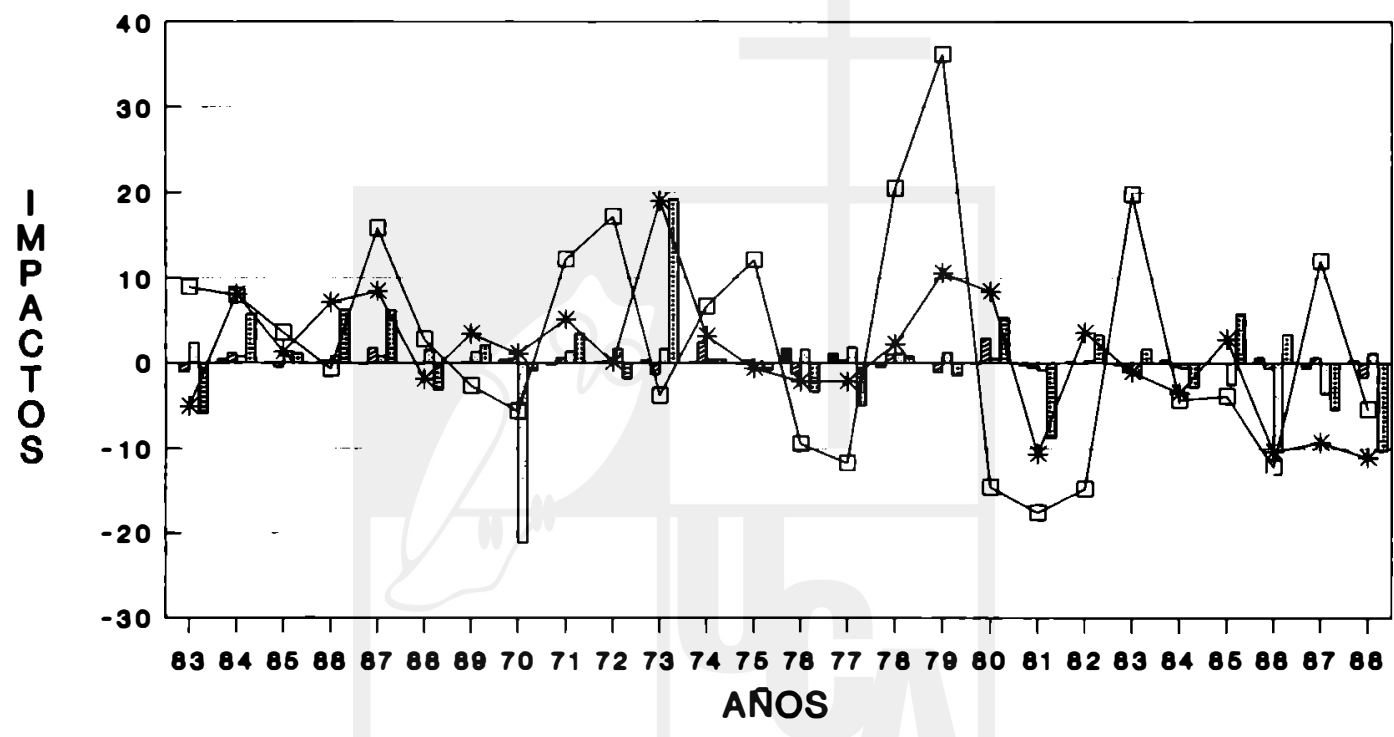

VARIABLES

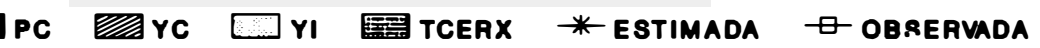


nala la función de exportaciones del enfoque keynesiano de Thirlwall y Hussain desarrollado en el primer capitulo. En este sentido, es de esperarse que los niveles de actividad económica en éstos dos paises, tengan una relación directa con los niveles de actividad de nuestra oconomia. Esto también tiene sus implicaciones desde el punto de vista de la política económica, ya que si en aquellos paises se realizan programas de ajuste, se podria considerar este efecto negativo para el caso de nuestra economia, si en el mismo instante to que nosotros queremos realizar es una política expansiva y no contractiva.

Con respecto a la variable ficticia, tenemos que su signo no es significativo, asi como también su signo positivo no coincide con lo esperado, pues de acuerdo a los datos observados, durante el periodo de crisis las exportaciones experimentaron un fuerte caída (ver más adelante el gráfico 8).

Con el análisis del gráfico 4, se pudo observar que a lo largo de todo el periodo en estudio, la variable que ejerce mayor influencia sobre la determinación de la tasa de crecimiento de las exportaciones es el tipo de cambio efectivo real. Siguiéndole en importancia se encuentra la variable que representa la demanda extema, que en algunos anos tiene un efecto sustancial sobre el nivel de la tasa de crecimiento de las exportaciones. En cuanto a los resultados estimados y observados de la variable podemos decir que con excepción de finales de los setenta, llevan la misma tendencia, es decir, que la estimación es bastante precisa.

En cuanto a la ecuación del crecimiento del PIB, el parámetro correspondiente a la inversión es significativo al $1 \%$, mientras que el de las otras dos variables 10 es al $5 \%$. Estando los signos de acuerdo con lo planteado por la teoria.

Por otro lado, podemos ver que los resultados nos confirman que cuando haya un incremento en la inversión en $1 \%$, ceteris paribus, el crecimiento de la producción será de $\mathbf{0 . 4 1 6 \%}$, lo cual es coherente con lo planteado por las teorias del crecimiento económico, con el modelo de las dos brechas y con el enfoque keynesiano. Esta baja elasticidad inversión del PIB, se debe al elevado coeficiente importado de las inversiones, que lleva a que el efecto multiplicador dentro de la economia se fugue al exterior. $Y$ también a la baja participación de la inversión dentro de la producción.

En cuanto a la influencia de las exportaciones, se observa que si hay un incremento de $1 \%$ en éstas, manteniendo los demás factores constantes, la producción se incrementará en $0.278 \%$, mostrando también una baja elasticidad, que se debe precisamente a la poca integra- 


\section{GRAFICO 5 \\ IMPACTOS ESTIMADOS SOBRE LA TASA DE \\ CRECIMIENTO DEL PIB 1963-1988}

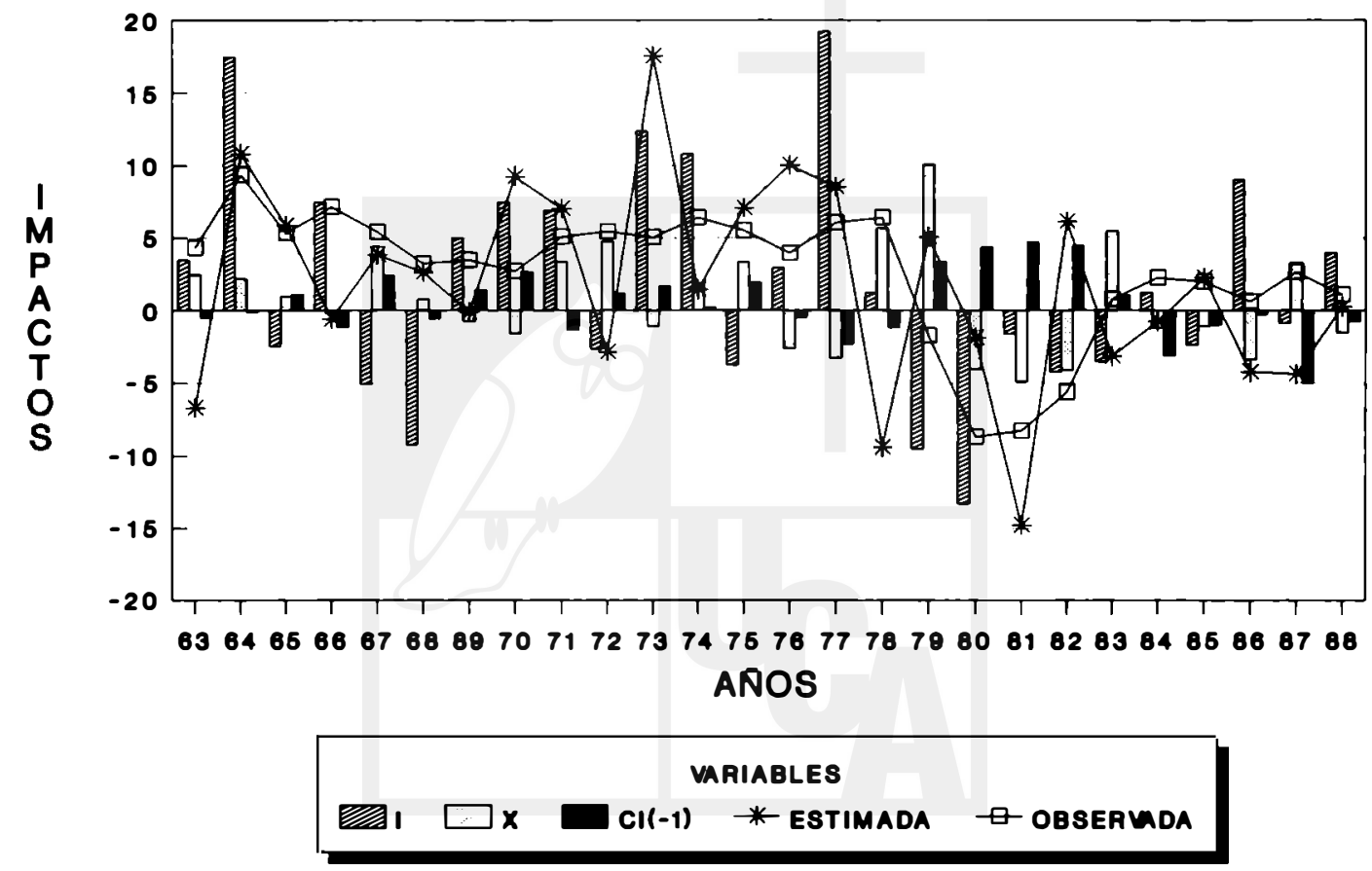

Digitalizado por Biblioteca "P. Florentino Idoate, S.J." 
ción del sector exportador con el resto de la economia, en cuanto demandante de insumos nacionales. Sin embargo, este resultado confirma lo propuesto por las teorias anteriores, ya que dada la enorme dependencia de nuestra economía de insumos importados, tenemos que un mayor acceso a las divisas a través de las exportaciones, tiene un efecto favorable sobre nuestra economia; además del efecto demanda que éstas puedan tener sobre el crecimiento económico, tal como to senala el enfoque keynesiano y las teorias clásicas del comercio internacional, y del enorme peso que tienen las exportaciones sobre la producción nacional. Detrás de esto se encuentra también un efecto indirecto, que es a través de los incrementos en el ahorro nacional, como resultado de los aumentos en las exportaciones, que viene a favorecer las posibilidades de financiamiento de la inversión, que a su vez ejerce su influencia positiva sobre el crecimiento económico, reforzando la incidencia de las exportaciones sobre el crecimiento económico. De esto se deriva que si existen dificultades en aumentar el crecimiento de las exportaciones, tal como to plantea la teoría de la CEPAL, entonces también habrán dificultades para el crecimiento económico.

Por el lado de la participación del crédito interno con un periodo de rezago en el PIB, tenemos que un incremento de $1 \%$ en ésta, me lleva a incrementos de $\mathbf{0 . 2 0 6 \%}$ en el crecimiento de la producción nacional, si los demás factores permanecen constantes. Lo cual sugiere que dicho factor tiene algún efecto sobre el crecimiento económico, a través de el acceso a los recursos financieros por parte de las empresas, sobre todo en el caso de El Salvador donde no existe un mercado de capital y las empresas deben financiar incluso su capital de trabajo mediante el crédito al sistema bancario.

Obsenando los resultados para la variable ficticia, tenemos que su signo es positivo, pero no es significativa, por lo cual el modelo no logra detectar el efecto negativo que ha tenido la crisis socio-politica de la década de los ochenta en el crecimiento de la producción en nuestro pals.

En cuanto a los impactos que ejercen las variables en la determinación de la tasa de crecimiento del PIB, tanto la inversión como las exportaciones juegan un papel fundamental. Asi, vernos que en el gráfico 5 las variaciones del PIB son influenciadas por ambas variables, y que mientras existen anos en que ejercen su influencia en el mismo sentido, hay otros anos en que éstas son contrarias, compensándose una con otra. Se aprecia claramente, que en los anos de 1979 a 1982 , ambas variables cayeron fuerternente, lo que se reflejó en la fuerte comtracción económica a principios de la década de los ochenta, mien- 
tras que en los mismo anos se trata de compensar dicha caida con una fuerte expansión del crédito interno. En cuanto a la relación entre la variable estimada y la observada se puede concluir que el ajuste logra bastante precisión.

Finalmente, en la ecuación del ahorro externo tenemos con respecto a los parámetros de las importaciones y de las exportaciones que son significativos a un nivel del $1 \%$ y el $2 \%$ respectivamente.

Estos resultados, nos indican simplemente que se tiene que recurrir al ahorro externo por lo asimetrla que existe entre el comportamiento de las importaciones y las exportaciones, como lo senala la teoria de la CEPAL. Asl tenemos que la elasticidad importaciones del ahorro externo, 4.378, es mucho más alta que la elasticidad exportaciones de la misma varlable, 3.060, demostrando que aunque las exportaciones y las importaciones crecieran a un mismo ritmo, la necesidad del ahorro externo persistirla, dado que si existe un déficit en términos absolutos on el sector externo, y tanto las exportaciones y las importaciones crecen a un mismo ritmo, entonces las primeras nunca alcanzarian a las segundas. Sin embargo este fenómeno se podría contrarrestar sólo cuando las exportaciones crezcan más rápido que las importaciones, 10 cual nos lleva a pensar que es indispensable buscar la forma de diversificar y promover las exportaciones en nuestro pais, asi como contimuar un proceso de sustitución de importaciones.

Con respecto a la variable ficticia, tenemos que no es significativa, pero su signo si concuerda con los esperado por la teoria, debido a que en el perlodo de crisis el déficit del sector extemo se incrementa, lo mismo que las necesidades de ahorro externo, lo que da como resultado un signo positivo. Sin embargo al igual que en el caso de la ecuación de la inversión, por derivarse de una identidad, no se puede concluir sobre la importancia de la variable ficticia en este tipo de ecuaciones.

En el gráfico 6, se aprecia la influencia que ejercen las tasas de crecimiento de las importaciones y las exportaciones sobre la tasa de crecimiento del ahorro externo, y se puede concluir que, a lo largo de todo el perlodo, la mayor influencia proviene de las importaciones. $Y$ por tanto, también en esta parte del análisis queda sustentada la teoria que plantea que la necesidad de flujos externos para financiar el crecimiento es producto de la mayor dinámica que presentan las importaciones en relación a las exportaciones, resultado del carácter trunco y concentrador de nuestra economla, lo que plantea la necesidad de transformación del aparato productivo salvadoreno, pretendiendo elevar los niveles de exportaciones y reducir, dentro de las posibilidades reales, 


\section{GRAFICO 6}

IMPACTOS ESTIMADOS SOBRE LA TASA DE CRE-

CIMIENTO DEL AHORRO EXTERNO 1964-1988

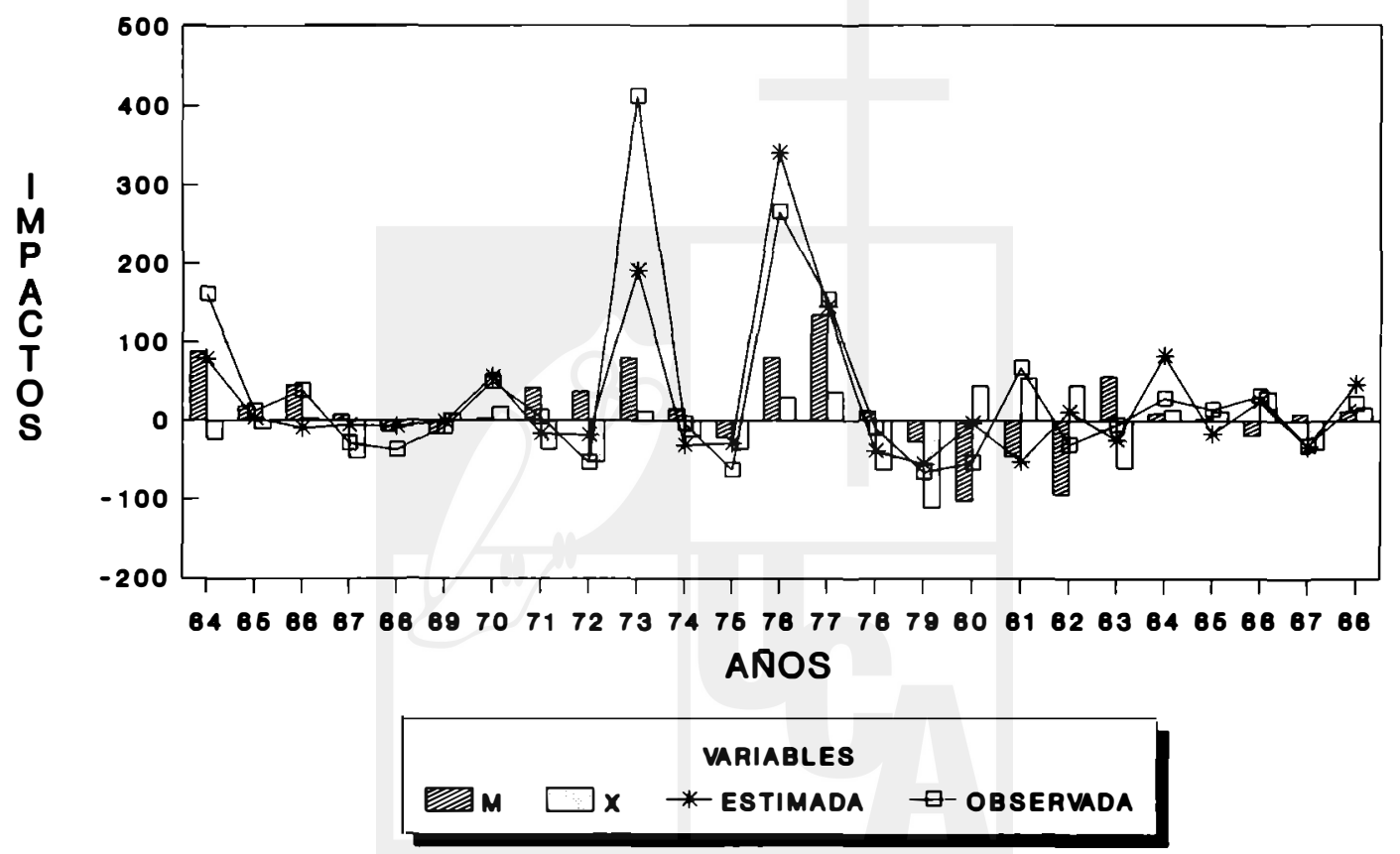

Omitimos los datos de 1963 porque

alteraban los demás resultados. 
los coeficientes de importaciones. Cabe mencionar que si bien es cierto que en algunos anos la necesidad de flujo de capital externo disminuye son mayores los anos que ésta se ve presente, además los montos necesarios de flujo externo para el crecimiento ecónomico salvadoreno son grandes lo cual nos permite una vez más afirmar el carácter dependiente de la economia.

Al igual que en las otras ecuaciones que conforman el modelo, podemos decir en cuanto a la relación entre la variable observada y la estimada que el modelo es capaz de permitimos explicar las tendencias de las variables.

También, viendo el modelo en su conjunto podemos ver cómo cada una de las variables afecta el crecimiento económico. Asi tenemos que la influencia que ejerce la tasa de interés internacional sobre las posibilidades de crecimiento económico, se da a través de la ecuación del ahorro, donde incrementos en esta variable reducen el crecimiento en el ahorro, lo que a su vez está reduciendo los fondos disponibles para el crecimiento de la inversión, y a través de esta última, se convierte en un factor que determina el crecimiento económico.

En el caso de los ingresos del sector no exportador, tenemos que pueden haber incrementos en el ahorro nacional a través de dos vias, la primera por el incremento de los ingresos en este sector, y la segunda por un aumento en los esfuerzos de ahorro por parte del mismo, que se reflejaria en el incremento de la elasticidad ingreso del sector no exportador del ahorro, lo que ampliaria los fondos necesarios para financiar la inversión, facilitándose el camino para el crecimiento económico.

La influencia de la inversión en el crecimiento económico a su vez, permite visualizar algunos de los determinates externos del crecimiento económico en nuestro pais. Se sabe que la inversión depende del ahorro nacional bruto y del ahorro externo, y que el primero está fuertemente influenciado por variables externas tales como las exportaciones y la tasa de interés internacional. $Y$ también, por el lado del ahorro externo, si la economia tiene acceso a éste, entonces habrá suficientes fondos para financiar la inversión y de esta forma se puede favorecer al crecimiento económico en nuestro país. $Y$, a su vez el ahorro externo también depende en gran medida de la dinámica de las exportaciones y las importaciones, por lo cual se vuelve también un factor importante para el funcionamiento de nuestra economia, reflejando el grado de determinación que tiene el sector externo sobre la inversión, que tiene su origen en las características estructurales de nuestro aparato productivo. Tal es el caso de carecer de un sector productor de bienes de in- 
versión y de bienes intermedios necesarios para el funcionamiento de la economla, obligando a que exista una elevada elasticidad ingreso de las importaciones, mientras que las exportaciones no dependen tanto de la capacidad productiva del pais, y tienen una tendencia a crecer más lentamente por su carácter primario.

A estas alturas es conveniente señalar, el carácter agregado de nuestro modelo, donde no hacernos ninguna distinción entre el ahorro y la inversión pública y privada. En el caso de la economia salvadorena esta distinción es relevante debido a que hay suficientes evidencias emplricas que demuestran que el déficit fiscal, la reducción en el ahorro público, ejerce una influencia bastante fuerte sobre el déficit en el sector externo. ${ }^{28}$ Lo cual hace pensar que gran parte del desequilibrio en el sector externo proviene del exceso de demanda interna, que proviene de los elevados gastos públicos destinados a mantener las condiciones necesarias para la acumulación de capital, con la creación de la infraestructura, y el apoyo a las inversiones privadas a través de le generación de economias externas y de las excensiones fiscales, todo ello unido al carácter extremadamente abierto de nuestro aparato productivo, lo que de alguna manera también ejerce presiones en cuanto a las necesidades de financiamiento externo.

Por el lado de las importaciones, también podemos encontrar efectos sobre el crecimiento económico. En primer lugar, la elevada elasticidad ingreso de las importaciones, hace que buena parte de la demanda se fugue al exterior, disminuyendo el efecto multiplicador al interior del pals. En segundo lugar, esta enorme dependencia de las importaciones, obliga a que el financiamiento de la inversión se realice en gran parte con ahorro externo, lo que deja fuera de nuestro alcance buena parte de nuestras posibilidades de acumulación. En tercer lugar, las rigidices internas en el sector productor de granos básicos, hace que periódicamente se tenga que recurrir a la importación de este tipo de bienes, agravando más el déficit en el sector externo, y reduciéndo aún más las posibilidades de crecimiento endógeno autosostenido. Finalmente, se observa que la sobrevaluación de la moneda, no ha ejercido una influencia significativa en el incremento de las importaciones, debido a que éstas dependen principalmente de los factores mencionados anteriormente.

Otro mecanismo adicional, que afecta el crecimiento económico son las exportaciones, que dependen de la demanda externa, fundametalmente la proveniente de Guatemala y Costa Rica, del tipo de cambio efectivo real, y de la producción y los precios del café. Fundamentalmente, su incidencia sobre el crecimiento económico en El Salvador, se 
da a través de dos vias. La primera, indirectamente, por la generación de ingresos con una elevada elasticidad a ahorrar, favoreciendo asl el aumento de los fondos disponibles para financiar la formación de capital. Y la segunda, más directamente, por el efecto demanda externa que ejerce sobre nuestra economia, por el incremento de la disponibilidad de divisas indispensables para el sostenimiento de la actividad económica, dado el estrangulamiento externo, y por el tamaño de su participación en la producción nacional.

Finalmente, se observa que el ahorro externo ejerce un papel fundamental en el crecimiento económico, aunque esta influencia es indirecta en nuestro modelo, ya que se da a través de la ampliación de los fondos para financiar la inversión, y mediante esta última se transmite su impacto sobre el crecimiento. Pero, también hay que tener en cuenta que las necesidades de flujos netos de capital extranjero, surgen del carácter trunco del aparato productivo, que obliga a recurrir permanentemente a las importaciones de bienes de capital y de insumos para la industria, mientras que la dinámica de las exportaciones es más limitada, por estar influenciada en gran parte por factores extemos. Esto último nos permite cuestionar el papel de la ayuda extranjera como fuente de financiamiento para el desarrollo, pues cuando la economia nacional crece se amplia el déficit externo y surge la necesidad de financiamiento, que al realizarse, reproduce la debilidad externa del aparato productivo, a menos que la ayuda extranjera esté canalizada a favorecer a aquellos sectores que tienden a promover las exportaciones y a sustituir importaciones.

\section{B. Análisls histórico de las Influencias entre las variables}

En esta parte, partiendo de las conclusiones que se derivan de los resultados obtenidos en la sección anterior, se hace un análisis histórico de las influencias entre las diversas variables que afectan el crecimiento de nuestra economia y de los determinantes externos sobre éstas.

Siguiendo el mismo orden comenzamos por el análisis de la inversión y el ahorro nacional. La inversión es financiada tanto por el ahorro nacional, $S$, como por el ahorro externo, $F$, si presentamos la contribución de cada una de dichas variables al financiamiento de la inversión, se observa en el gráfico 7, que tanto en la década de los sesenta como de los setenta el ahorro nacional es la fuente de mayor importancia, cubriendo más del cincuenta por ciento de ésta. Sin embargo, esta relación se invierte a partir de la década de los ochenta, 
GRAFICO 7

EL SALVADOR: PARTICIPACION DEL AHORRO NACIONAL Y EXTERNO EN LA INVERSION 62-88

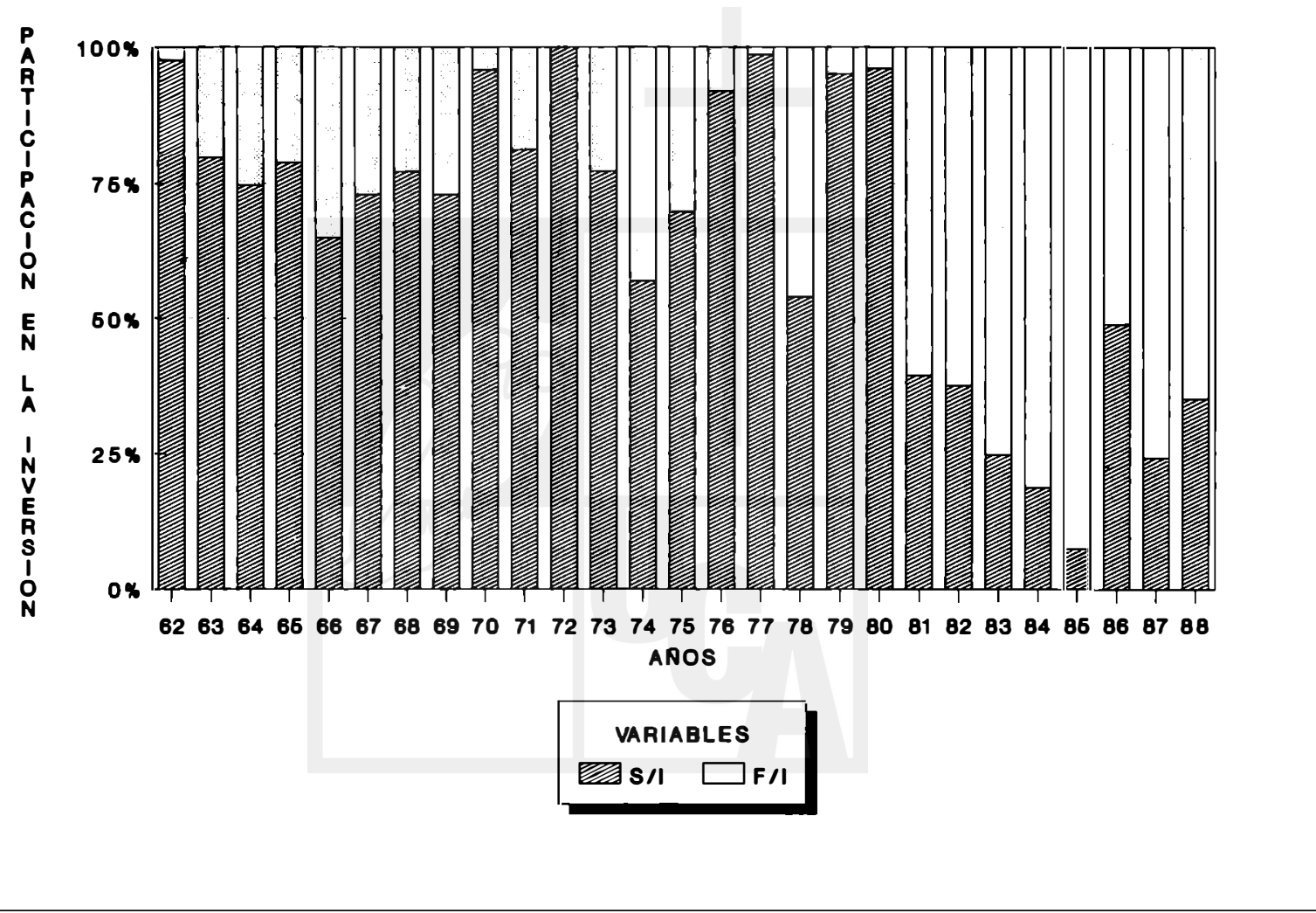

Digitalizado por Biblioteca "P. Florentino Idoate, S.J."

Universidad Centroamericana José Simeón Cañas 
cuando comienza la crisis generalizada en nuestro pais, donde es el ahorro externo el que cubre más del cincuenta por ciento del financiamiento de la inversión, convientiéndose en un elemento fundamental para el sostenimiento de la actividad económica. Uniéndo esta observación a los resultados obtenidos en la sección anterior, podemos asegurar que debido a la influencia que cobra el ahorro externo sobre la inversión en la última década, de no haber existido tales magnitudes de flujo de ahorro externo la contracción en la economia habría sido mucho más grande. Además, como señalamos más arriba, podemos asociar este fenómeno al creciente déficit fiscal que caracteriza a la década de los ochenta, pues la disminución en la participación del ahorro nacional, se debe explicar en buena parte por la caida del ahorro del sector público, considerando que los saldos negativos de las cuentas en este sector pueden absober alguna parte del ahorro privado; sin embargo este no ha sido el caso en nuestro pais por el enorme flujo de ahorro externo, que logra compensar la caida del ahorro en el sector público.

En cuanto al comportamiento de las exportaciones e importaciones, tenemos que en la mayoria de años que cubre el periodo de estudio, la relación de las importaciones con el PIB es mayor que la de las exportaciones, mostrando la tendencia estructural que tiene nuestra economia a mostrar déficits en el sector externo (ver gráfico 8). También tenemos que ésta relación sufre un incremento de la década de los sesenta a la década de los setenta, con una mayor apertura externa de nuestra economia para esta última, reflejando en cierto sentido, las limitaciones del proceso de sustitución de importaciones que caracterizó al periodo del mercado común centroamericano, y a los intentos posteriores de solventar su decadencia a través de políticas fiscales expansionistas y de una política de mayor apertura a la penetración de capitales extranjeros. ${ }^{29}$ Pero en la década de los ochenta la caida de ambas es pareja, mostrándose sin embargo, que la diferencia entre las dos variables se agudiza, reflejo de la crisis del periodo y de la cuantiosa ayuda externa que ayudó a solventar temporalmente el problema.

Por el lado de la relación entre el ahorro nacional y las exportaciones, si graficamos la participación de cada una de estas variables con respecto al PIB, ver gráfica 9, se observa que es bastante estrecha, reforzando los resultados que obtuvimos en el modelo. Asi tenemos que mientras la relación se mantiene más o menos estable para ambas variables en la década de los sesenta, en la siguiente década se experimenta un alza en las exportaciones, que explica a su vez el incremento de la relación ahorro nacional-PIB, hasta llegar a 1978. De 


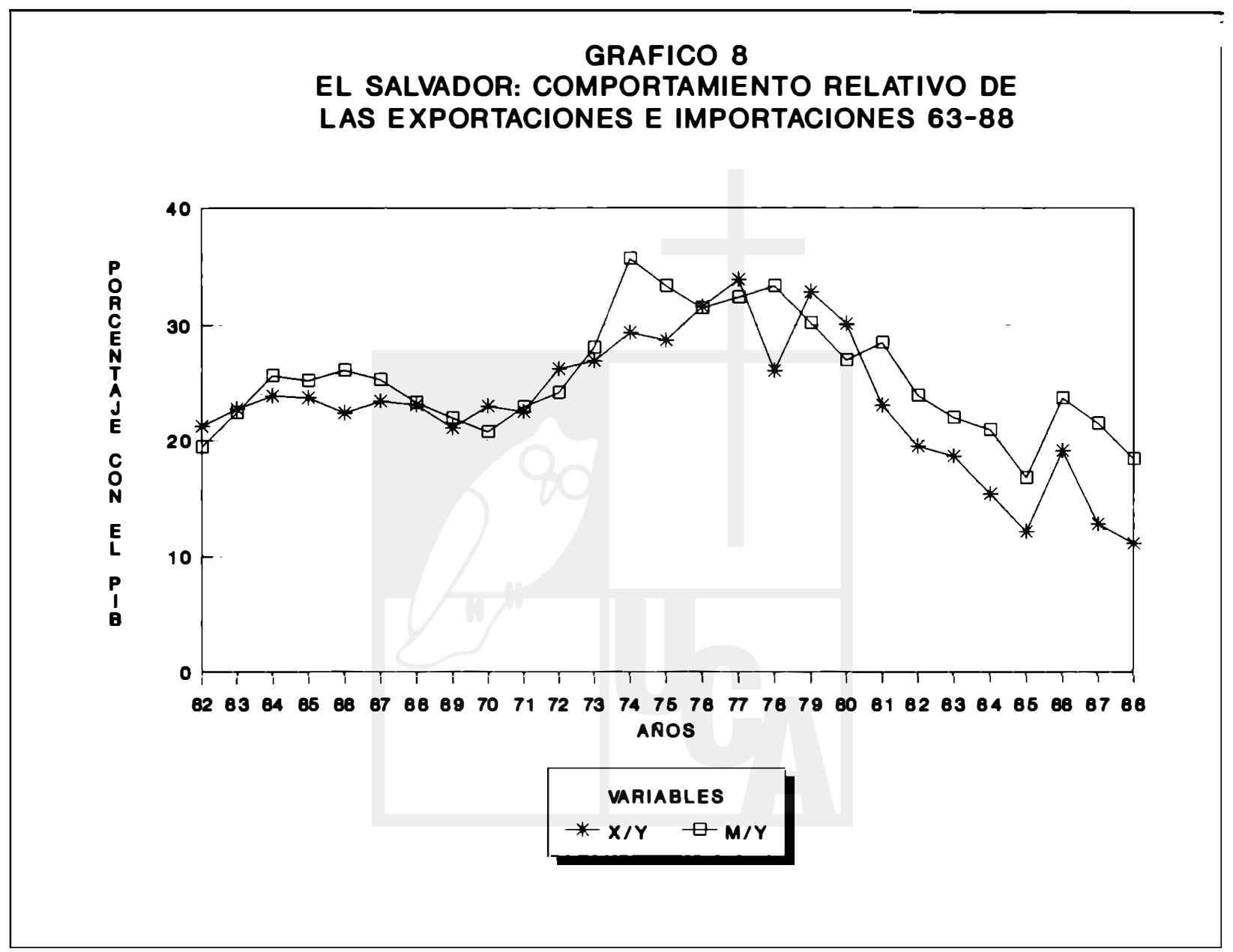

Digitalizado por Biblioteca "P. Florentino Idoate, S.J."

Universidad Centroamericana José Simeón Cañas 


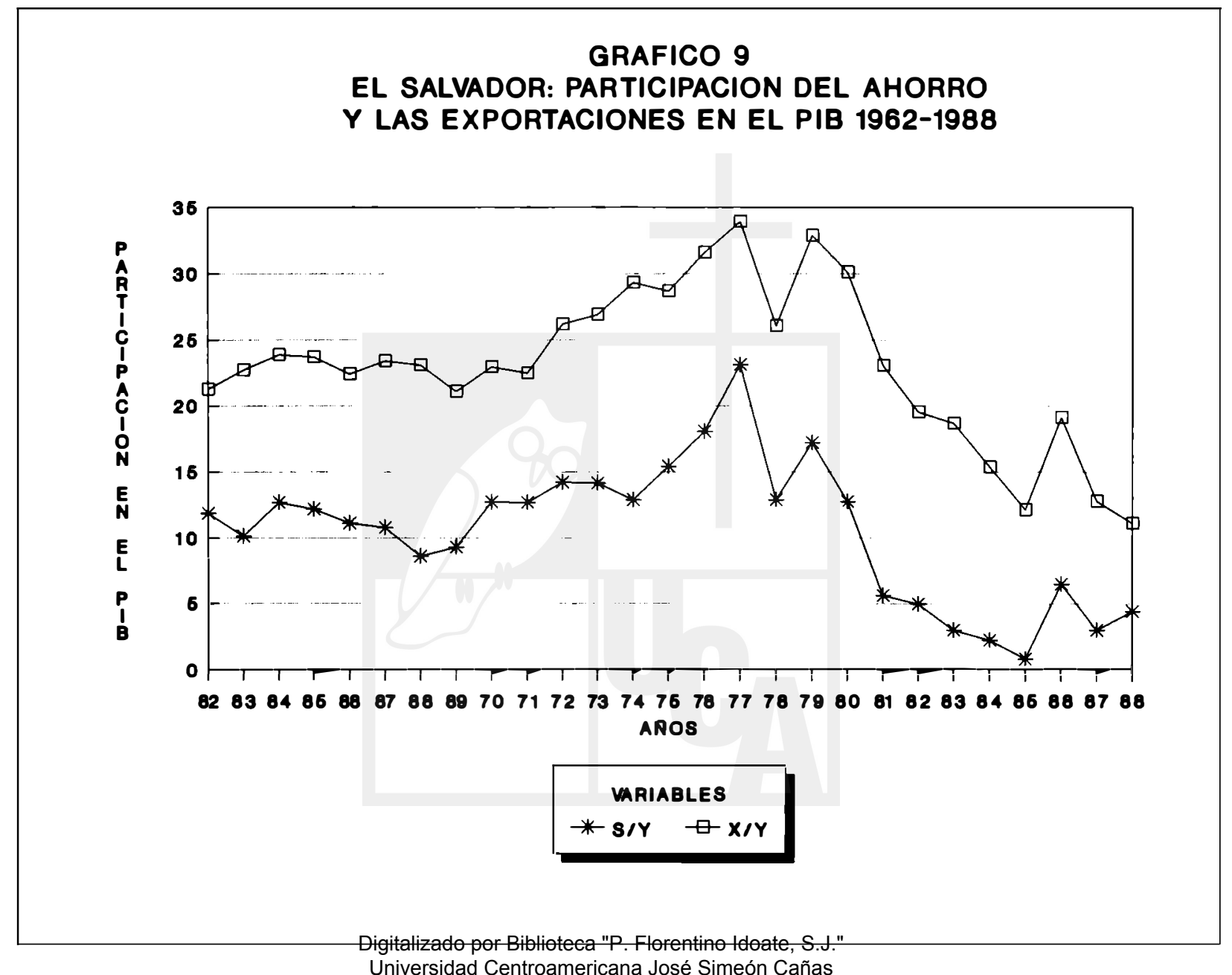


este ano en adelante, las exportaciones experimentan una fuerte caida, que se ve reflejada a su vez en la reducción del ahorro nacional por los menores ingresos para el sector exportador, y por la menor recaudación fiscal proveniente del café a lo largo de esta década, incidiendo seriamente en el déficit del sector público, con excepción de 1986 donde se da una leve recuperación por lo mayores precios del producto en ese ano. $Y$ es precisamente en esta etapa donde el ahorro externo se convierte en un factor importante para el sostenimiento de la actividad económica, porque justo con la reducción de las exportaciones, manteniéndose siempre elevados niveles de déficit en el sector externo, ya no sólo es necesario recurrir al ahorro externo para financiar un déficit comercial, sino que también es necesario recurrir al mismo para poder mantener los niveles de inversión, o para que al menos su reducción no sea devastadora, ya que el ahorro nacional se contrajó por la relación que guarda con las exportaciones.

Esto último, se puede explicar mejor recurriendo a dos gráficos más. El gráfico 11, muestra que la relación entre la participación de la inversión en el PIB y la tasa de crecimiento de este último es bastante estrecha en las dos primeras décadas, mientras que en la última, la relación inversión-PIB muestra una tendencia decreciente desde 1979 hasta 1987, cuando por el otro lado, el PIB muestra una caida en los primeros cuatro anos, de 1979 a 1982, experimentado una pequena recuperación en los anos siguientes, donde mantiene niveles de crecimiento positivos, aunque bajos. Esta separación entre el comportamiento de la relación inversión-PIB y la tasa de crecimiento del último, se ve explicada por el enorme flujo de ahorro externo en la década de los ochenta, que puede ser observado en el gráfico 10, donde la relación ahorro externo-PIB muestra un comportamiento diferente al de la tasa de crecimiento del PIB, hasta 1980, y de alli en adelante el comportamiento de ambas variables es bastante semejante, corroborando las ideas anteriores. El hecho de que la dependencia del financiamiento externo se tome más significativa en la década de los ochenta, mientras la apertura de la economía se reduce por la caida en los niveles de importaciones y exportaciones, se explica por la fuerte caida del ahorro nacional, que exigió que penetraran flujos de capital extranjero para poder sostener los niveles de actividad económica, y por el hecho de que aunque se redujeron tanto la participación de las exportaciones en el PIB, como la de las importaciones, el déficit en el sector externo fue mayor que en las décadas anteriores, como se observó en el gráfico 8.

En conclusión, se observa que la prinicipal fuente de financiamiento de la inversión tiene su origer: en el ahorro nacional hasta finales de la década de los setenta, mientras que en los ochenta la principal fuente 
GRAFICO 10

COMPARACION ENTRE LA TASA DE CRECIMIENTO

DEL PIB Y LA RELACION F/Y 1963-1988

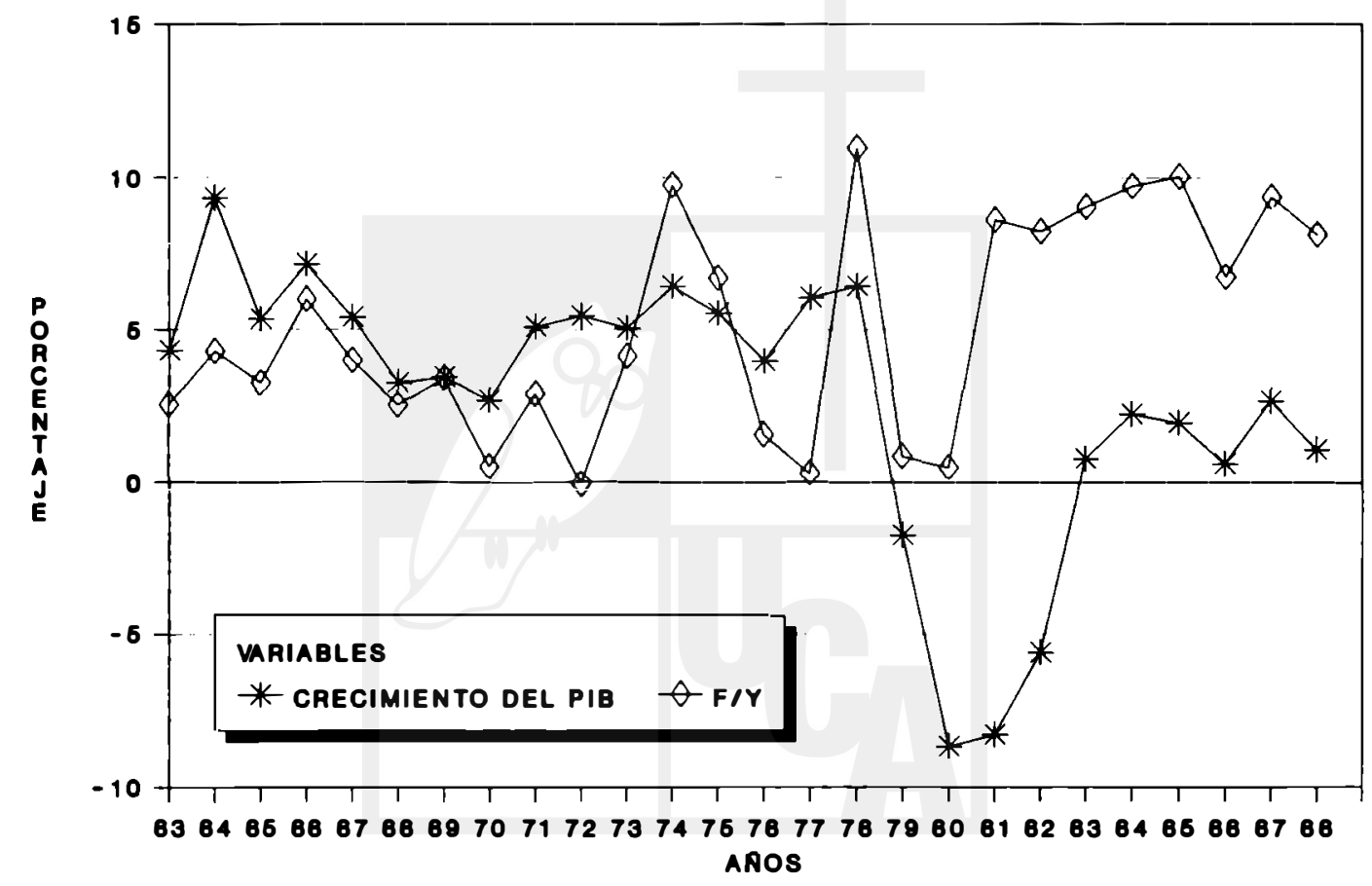

Digitalizado por Biblioteca "P. Florentino Idoate, S.J."

Universidad Centroamericana José Simeón Cañas 


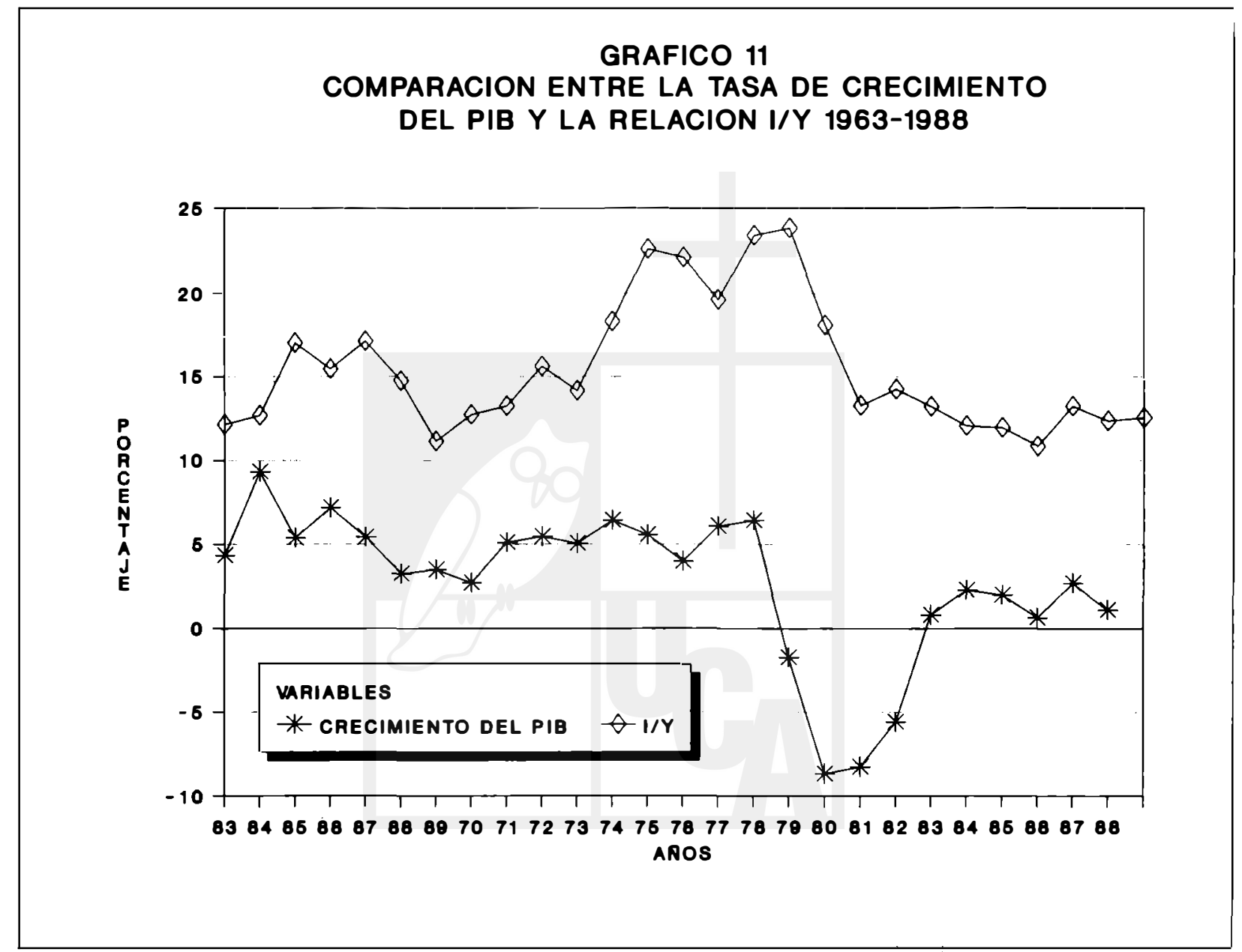

Digitalizado por Biblioteca "P. Florentino Idoate, S.J."

Universidad Centroamericana José Simeón Cañas 
de financiamiento proviene del ahorro externo. La apertura externa de nuestra economia se mantiene más o menos estable a lo largo de la década de los sesenta, elevándose en la de los setenta, y disminuyendo en la de los ochenta, pero mostrando en todo el periodo que hay una tendencia a recurrir en permanentes déficits de balanza de bienes y servicios, sobre todo en la última década. También se observa el alto grado de dependencia del ahorro nacional de los ingresos provenientes de las exportaciones, viendose que ambas variables se mueven paralelamente a lo largo del tiempo. Que la relación entre los niveles de inversión y el crecimiento económico es bastante estable hasta 1979 , donde se presenta una separación entre ambas, reduciéndose la primera a lo largo de la década de los ochenta, mientras que el crecimiento de la producción se contrae al inicio, mostrando un moderado crecimiento a partir de 1983. Situación que se explica por el estrecho vinculo que existe entre los niveles de ahorro externo que llegaron a la economia en los mismos años, y la misma tasa de crecimiento, demostrando que es esta variable (el ahorro externo) la que explica la modesta recuperación en la producción.

\section{Conclusiones}

Del análisis anterior se derivan las siguientes conclusiones:

1. Que en El Salvador el ahorro nacional es sumamente dependiente de los ingresos que provienen del sector exportador, a lo largo del periodo 1962-1988, debido a la elevada concentración del ingreso en dicho sector y a la mayor facilidad en la captación de impuestos provenientes de las exportaciones, sobre todo las del café, lo cual favorece los niveles de ahorro en el sector público. Mientras que su dependencia de los ingresos del sector no exportador y de la tasa de interés intemacional es menor.

Esto a su vez, afecta el crecimiento económico a través de los recursos disponibles para financiar la inversión. Lo cual, hace pensar que de quererse incrementar los niveles de ahorro nacional con fines de crecimiento económico, se tiene que hacer un mayor esfuerzo por crear nuevas fuentes de ingresos que tengan su origen en la producción de bienes destinados al mercado intemo, y que el esfuerzo de ahorro por parte del sector público deberia volcarse también hacia la captación de impuestos directos, sobre todo en aquello rubros que hacen más progresiva la recaudación fiscal, para reducir el grado de vulnerabilidad externa.

2. Que la inversión está altamente determinada por factores externos a través de dos mecanismos. El primero, por depender del ahorro 
nacional, que es una variable vulnerable a variables externas a través de las exportaciones y la tasa de interés internacional. $Y$ el segundo, por el ahorro extemo, dado que en nuestra economia la brecha comercial es dominante como factor limitante del crecimiento económico. Las medidas de política económica que se derivan de esto, son las mismas que se senalaron en el caso del ahorro nacional, y las que se senalan más abajo para el ahorro externo.

3. Que existe en nuestra economia un elevado coeficiente de elasticidad ingreso de las importaciones (1.27), lo que se deriva del carácter trunco del aparato productivo y de los patrones de consumo adoptados por algunos grupos de la población. Además, que los niveles de las importaciones tienen que ser mayores cuando se presentan rezagos en el sector productor de granos básicos. Mientras que las relaciones de precios y de tipos de cambio, reflejados en la variables del tipo de cambio efectivo real ponderado con las importaciones, no parecen tener una influencia importante en el crecimiento de las mismas. En este sentido habria que atacar el problema del estrangulamiento externo por tres vias: la búsqueda de una mayor anticulación del aparato productivo mediante la producción de una mayor cantidad de insumos y bienes de capital en territorio nacional; una política agricola que garantice los niveles de producción de granos básicos para el consumo de la población; y, una selectividad en el manejo de las divisas y en la política arancelaria, evitando que se dediquen divisas escasas, a la importación de bienes suntuarios.

4. Las exportaciones dependen en gran medida de la demanda externa, fundamentalmente de los principales socios comerciales centroamericanos, Guatemala y Costa Rica, y del tipo de cambio efectivo real. Mientras que la evidencia en cuanto a la producción en el sector cafetalero y los precios del café como determinantes de las exportaciones, no es muy significativa, lo cual no implica rebajar la importancia de estas variables, dada la elevada participación de este producto en el total de nuestras exportaciones. Estos resultados, indican hasta cierta punto el carácter exógeno de nuestras exportaciones, donde nuestra capacidad de intervención en los volúmenes y los valores de éstas es limitada. En base a esto, se sostiene que si se quiere llevar a cabo una polltica de promoción de exportaciones, el esfuerzo tiene que ser bastante grande, en cuanto a la creación de mecanismos que permitan ejercer algún control sobre éstas, y que para mientras es conveniente utilizar la base del sector primario exportador, para la captación de divisas. También es importante destacar la importancia de aprovechar los estrechos vínculos con los países centroamericanos para desarrollar el comercio interregional. 
5. El crecimiento económico en El Salvador es sumamente vulnerable a las fluctuaciones de variables externas a través de diversos mecanismos. En primer lugar, a través de la inversión, debido a que como se senaló más arriba, ésta depende en gran parte de factores externos, tanto a través del ahorro nacional, como a través de los flujos de capital extranjero, los cuales cobran una gran relevancia sobre todo en la década de los ochenta. De las exportaciones, a través de la demanda que éstas implican al interior de la economia, y como fuente de divisas que permiten la importación de los insumos y bienes de capital indispensables para el sostenimiento de la actividad económica. Y que la influencia de éstas dos variables sobre el crecimiento económico es reducida por el elevado coeficiente de elasticidad ingreso de las importaciones. En este sentido, toda política económica que se quiera llevar a cabo, con fines de reactivación tiene que preocuparse por considerar estos mecanismos, reduciendo la vulnerabilidad de la inversión a los factores extemos, y desarrollando una política que favorezca más el comercio con los paises centroamericanos, dada la estrecha interdependencia que existe entre estos países. Junto con el esfuerzo adicional en la reducción del coeficiente de importaciones.

6. Existe evidencia en el modelo presentado anteriormente, de que hay un comportamiento asimétrico entre exportaciones e importaciones que lleva a nuestra economia a incurrir en la necesidad del financiamiento externo para poder sostener los niveles de actividad económica, lo cual sugiere que el ahorro externo más que una forma para financiar el desarrollo económico es uno de los mecanismos que tiende a reproducir una de las debilidades del aparato productivo, en tanto que permite ir postergando los cambios estructurales necesarios en éste para reducir la vulnerabilidad externa de nuestra economia. Además, para reducir tal vulnerabilidad es necesario que las exportaciones crezcan a una mayor velocidad que las importaciones, debido a que la elasticidad importaciones del ahorro externo es mayor que la elasticidad exportaciones del mismo.

\section{Notas}

1. Este trabajo es una adaptación para articulo de nuestra tesis de graduación "Determinantes externos del crecimiento económico en El Salvador 1962-1988. Un modelo econométrico aplicado a la economía salvadoreña", donde se han omitido algunas partes y afinado otras. Por razones de espacio los datos utilizados, los resultados de las estimaciones y los cálculos de los impactos de algunas variables sobre otras no serán publicados, el lector interesado los podrá encontrar en los apéndices de la tesis mencionada 
2. Vease R. Dornbusch y S. Fischer, "Macroeconomla", McGraw-Hill, 1985, pág. 49-53.

3. Departamento de Economla. "Dinámica y crisis de la economla salvadorểa". Estudios Centroamericanos, ECA, enero-febrero 1986, pág. 19.

4. M. Kaleckl, "Ensayo sobre las economlas on vias de desarrollo". Grupo Editorial Grijalbo, 1980, pág.

5. M. Kalecki, "El problema del financiamiento del desarrollo económico". en J. A. Ocampo, "Economla poskeynesiana". FCE, 1988, pág. 514-535.

6. R. Rivera, "Producción de alimentos y desbalances macroeconómicos". Roelidad económico-social, Aho II, septiembre-octubre 1989, pág. 446-447.

7. Presentamos un resumen de las críticas que se hacen a los estudios que han aplicado el modelo de las dos brechas on el APENDICE I de la tesis en que se basa este articulo.

8. Ver por ejemplo, L. R. Cáceres, "Endeudamiento extemo y crecimiento oconómico: el caso de Guatemala'. Seminario del INCAE, noviembre de 1989, pág. 1-56.

9. Ver por ejemplo los trabajos, B. B. Aghevli, y M. S. Khan, "Government Deficits and the Inflationary Process in Developing Countries". IMF Staff Papors, Vol. 25, September 1978, pág. 383-416. Y, M. S. Khan y M. D. Knight, "Stabilization Programs in Developing Countries: A Formal Framework". MF Staff Papers, Vol. 28, March 1981, pág. 1-53.

10. Ver tambión R. Rivera, "Inflación y desbalances...", op. cit. pág. 447.

11. El tipo de cambio efectivo real es cuando relacionamos nuestro tipo de camblo con una canasta de tipos de cambio de los principales socios $c^{\circ-}$ merciales, y las relaciones de precios, mediante una ponderación. Es meJor realizar esta ponderación con la participación de las importaciones proveniemtes de cada pals en las importaciones totales, cuando se trata de una ecuación de importaciones, y realizar la ponderación con las exportaciones cuando se trata de una ecuación de exportaciones. De ahl que utilicomos TCERM, como el tipo de cambio efectivo real ponderado con las importaciones, y TCERX, como el tipo de cambio efectivo real ponderado con las exportaciones.

12. En nuestra ecuación de exportaciones, de acuerdo a la teoria, habrla un problema de multicolinealidad por la relación que existirla entre precios y producción de calé. Pero en nuestro caso el coeficiente de correlación entre ambas variables es bastante bajo, 0.002 , por lo que no es necesario expresar alguna de dichas variables como proporción de una tercera.

13. Véaso, N. N. Saca, "Pollticas de estabilización económica en palses subdesarrollados: un modelo aplicado a la economía salvadoreña". Boletín de ciencias económicas y sociales, año $X$, mayo-junio de 1987, pág. 145 y 162.

14. En el caso de un saldo negativo en la cuenta de capitales, por ejemplo cuando las nuevas entradas de capital extranjero son menores que el servicio de la deuda externa, las importaciones del pals se disminuirán, lo que irá en detrimento de su crecimiento económico, manifestándose en una brecha externa menor. Por lo que siempre se justificarla trabajar con 
la balanza comercial de bienes y servicios para determinar lo que son los flujos netos de capital extranjero, o lo que es el ahorro externo.

15. En el caso de los modelos económicos simultáneos, se diferencia entre la forma estructural del modelo donde se exponen las diferentes ecuaciones de comportamiento de las variables endógenas, y la forma reducida donde se plantea la solución del modelo dejando todas las variables endógenas en función de las exógenas, y a partir de las cuales se pueden obtener multiplicadores totales. Al respecto ver Stewart, Mark B. y Kenneth Wallis. "Introducción a la econometrla". Alianza editorial, España 1984. Págs. 1330.

16. Además, la estimación de modelos simultáneos requiere que se haga una correcta identificación de éstos, de manera que cumplan las condiciones de orden y de rango. En nuestro modelo dichas condiciones se cumplen. Para una explicación del problema de la identificación y sobre los métodos de estimación de ecuaciones simultáneas ver Gujarati (1981), pág. 367.

17. En Agheveli y Khan (1978) se sostiene que la interpretación del coeficiente de determinación en modelos simultáneos no es muy clara y que al respecto hay otros estadisticos para determinar la bondad del ajuste del modelo, entre los cuales está el error cuadrático medio dividido entre la varianza de la variable dependiente en cada una de las ecuaciones.

18. Sin embargo hay que observar que el coeficiente que acompaña al ingreso del sector no exportador no es significativo, mientras que el que acompaña a los ingresos del sector exportador sf lo es.

19. "Según la compañla Salvadoreña del Café, en 1971, habia 743 caficultores con producciones mayores a los 1000 quintales oro por cosecha. Estos representaron el 6.6 por ciento de los productores totales y concentraron el 76.24 por ciento de la producción." en S. Arias Peñate,"Los subsistemas de agroexportación en El Salvador. El café, el algodón y el azucar'. UCA editores, 1988. Pág.111.

20. En cuanto a la relación significativa que existe entre ahorro nacional $\theta$ ingresos del sector exportador, no hay que descartar la posibilidad de que exista un efecto contable, dado que el ahorro nacional se mide como la inversión menos el ahorro externo $(S=I$ - F), lo cual trae como consecuencia que al haber aumento en las exportaciones, también habrá un incremento en el ahorro, aunque las importaciones y la inversión también varlen, ya que estas dos últimas generalmente lo hacen en el mismo sentido. Esto, sin embargo, no le resta importancia al análisis que planteamos.

21. Según Cáceres (1990), la relación negativa entre la tasa de interés internacional y el ahorro nacional se da a través de la fuga de capitales del pais, afectando negativamente el ahorro nacional, argumentando que "la formación de ahorro... está en parte determinada por el comportamiento de variables fuera del control de las autoridades económicas...;además, el atto costo del dinero a nivel internacional inhibe la formación de inventarios de los productos primarios, lo que deprime sus precios y el ingreso por exportaciones, afectándose asl negativamente el ahorron.Véase. L. R. Cáceres, "Notas sobre el endeudamiento...". Op. cit. pág.15-16. 
22. Los impactos estimados de las variables explicativas de cada ecuación sobre la variable estimada son calculados a partir de las estimaciones realizadas, por lo cual no deben entenderse como una medida exacta. Además para tener una idea de los alcances de las estimaciones, en cuanto a su presición, en los gráficos que presentamos a continuación colocamos también la variable observada, para que se tengan las reservas del caso.

23. Una explicación de este fenómeno está desarrollado más claramente en el APENDICE I, dedicado a las críticas que se han hecho a los estudios que tratan de aplicar el modelo de las dos brechas. Concretamente ver la critica 7.

24. Ver R. Rivera, "Producción de alimentos y desbalances..." op. cit. pág. 447.

25. Ver los estudios de Rivera, Roberto. "La inflación en El Salvador". Realidad económico-social. Año I, No.1, enero-febrero 1988. Págs. 7-56. Y, Rivera, Roberto y Nolvia Saca, "Políticas de estabilización y deuda externa en El Salvador". Boletin de ciencias económicas y sociales. Año X, No. 5 , septiembre-octubre 1987. Págs. 315-369.

26. Estamos concientes de que estos resultados no eran de esperarse, pués debido a las caracteristicas estructurales de la economía salvadoreña, y especificamente la extrema dependencia de las exportaciones de café, se esperaba encontrar buenos resultados. Esto nos sugiere que se requiere profundizar más en los mecanismos concretos a través de los cuáles la producción y los precios del café se convierten en variables que ejercen influencia sobre los grandes agregados económicos de nuestro país.

27. A diferencia del tipo de cambio efectivo real, la demanda externa quedó representada únicamente por estos dos paises porque las interrelaciones entre éstos y la economia salvadoreña son bastante fuertes, mientras que las exportaciones nuestras hacia los paises industrializados son una parte insignificante de sus importaciones, por lo cual no es de esperarse que incrementos en sus ingresos se traduzcan en mayores demandas para nuestros productos, además de que la elasticidad ingreso de sus importaciones que provienen de nuestros paises son bajas, como lo señalan la teorla de la CEPAL y la ley de Engel. En el caso del tipo de cambio efectivo real la situación es distinta, pues aquí si es relevante la consideración de todos los países, como principales socios comerciales, pues lo que nos está vinculando son los precios internos de nuestro país y los precios a que pueden venderse nuestros bienes en el extranjero, dependiendo del tipo de cambio.

28. Al respecto ver los trabajos de Peraza, Gerardo, et. al. "Mecanismos de transmisión del déficit fiscal al desequilibrio externo, en la economía salvadoreña. Perlodo: 1960-1986", Tesis de grado, UCA. Septiembre 1988.

Rivera, Roberto. "La evolución reciente de la economian. ECA, Año XLIII, No. 471-472, Enero-febrero 1988. Págs. 47-60.

Saca, Nolvia y Roberto Rivera. "Políticas de estabilización y deuda externa en El Salvador". Boletin de ciencias económicas y sociales, Año X, No. 5 , Septiembre-octubre 1987. Págs. 315-369.

29. López, José Roberto. "Industrialización y urbanización en El Salvador 1969-1979. UCA editores, El Salvador 1984. Pág 45-92. 


\section{Blbllografia}

1. Aghevli, Bijan B. and Mohsin S. Khan, "Government Deficits and the Inflationary Process in Developing Countries". IMF Staff Papers. Vol. 25, September 1978, p. 383-416.

2. Arias, Salvador, "Los subsistemas de agroexportación en EI Salvador. EI café, el algodón y el azúcar". UCA editores, El Salvador 1988. 416 págs.

3. Bruton, Henry J., "The Two Gap Approach to Aid and Development: Com. ment". The American Economic Review. Vol. 59, No. 3, June 1969, p. 439 446.

4. Cáceres, Luis René, "Endeudamiento externo y crecimiento económico: el caso de Guatemala". Seminario del INCAE, 9 de noviembre de 1989, 54 p.

5. "Notas sobre el endeudamiento externo de Honduras". Seminario del INCAE, febrero de 1990, 26 p.

6. Chenery, Hollis B., "The Two Gap Approach to Aid and Development: A Reply to Bruton". The American Economic Review, Vol. 59, No. 3, June 1969, p. $446-449$

7. y Michael Bruno, "Development Alternatives in an Open Economy: the Case of Israel". The Economic Journal, Vol. 72, No. 285, March 1962, p. $79-103$

8. y Peter Eckstein, "Development Alternatives for Latin America". Journal of Political Economy Vol. 78, No. 4, Supplement to July/August 1970, p. 966-1006.

9. y Alan M. Strout, "Foreign Assistance and Economic Development". The American Economic Review, Vol. 56, September 1966, No. 4, Part. I, p. 679-733.

10. "Foreign Assistance and Economic Development: Reply." The American Economic Review, Vol. 58, No. 4, September 1968, p. 912-915.

11. Cohen, Benjamin I., "Foreign-Exchange Constraints in Economic Development and Efficient Aid Allocation: Comment". The Economic Journal, Vol. 76, No. 301, March 1966, p. 168-170.

12. Departamento de Economia, "Dinámica y Crisis de la Economía Salvadoreña", Estudios Centroamericanos, (ECA), enero-febrero, 1986, págs. 18-32.

13. Dornbusch, Rudiger y Stanley Fischer, "Macroeconomia", México, McGraw-Hill, 1985, 776 págs.

14. Feiwel, George R., "Michal Kalecki: Contribuciones a la Teoría de la Polftica Económica". Mexico, Fondo de Cultura Económica, 1981.

15. Gujarati, Damodar,"Econometría básica", McGraw-Hill, México 1981.

16. Hirschman, Albert O.," The Strategy of Economic Development", Yale University Press, 1958, p. 217.

17. Ibisate, Francisco Javier, "El modelo económico salvadoreño en la matriz insumo-producto: 1978", Boletín de ciencias económicas y sociales, Año V, septiembre-octubre 1986, págs. 264-292. 
18. Joong - Koon Lee, "Export and The Propensity to Save in L.D.C.S.". The Economic Journal, Vol. 81, No. 321, March 1971, p. 341.

19. Kalecki, Michal, "Ensayos sobre las economias en vias de desarrollo", Editorial Crítica, Barcelona, España, 1980.

20. ___ "El problema del financiamiento del desarrollo económico", en José Antonio Ocampo, "Economía poskeynesiana". Fondo de Cultura Económica, México 1988, p. 514-535.

21. Khan, Mohsin y Malcolm D. Knight, "Stabilization Programs in Developing Countries: a Formal Feamework". IMF Staff Papers, Vol. 28, March 1981, p. 1-53.

22. López, José Roberto, "Industrialización y urbanización en El Salvador: 1969-1979", UCA editores, El Salvador 1984, 186 págs.

23. Marshall, Jorge, "El modelo de las dos brechas y América Latina", CEMLA, 1970, 66 p..

24. McKinnon, Ronald I., "Foreign Exchange Constraints in Economic Development and Efficient Aid Allocation". The Economic Journal, June 1964, Vol. LXXIV, No. 294, p. 388-409.

25. "Foreign Exchange Constraints in Economic Development and Efficient Aid Allocation: Rejoinder". The Economic Journal, Vol. 76, No. 301, March 1966, p. 170-171.

26. Mickesell, Raymond y James E. Zinser, "The Nature of the Savings Function in Developing Countries: A Survey of the Theoretical and Empirical Literature". The Journal of Economic Literature, Vol. 11, March 1973, No. 1. p. 1-26.

27. Papanek, Gustav F., "The Effect of Aid and Other Resource Transfers on Savings and Growth in Less Developed Countries". The Economic Journal, Vol. 82, No. 327, September 1972, p. 934-950.

28. "Aid, Foreign Private Investment, Savings, and Growth in Less Developed Countries". Journal of Political Economy, Vol. 81, No. 1, JanFeb. 1973, p. 120-130.

29. Peraza, Gerardo, et. al., "Mecanismos de transmisión del déficit fiscal al desequilibrio del sector externo, en la economía salvadoreña periodo: 1960-1986", Tesis de grado, UCA 1988, 129 págs.

30. Ram, Rati, "Exports and Economic Growth: Some Additional Evidence". Economic Development and Cultural Change, Vol. 33, No. 2, January 1985, p. 415-425.

31. Rivera, Roberto, "La inflación en El Salvador". Realidad económico-social, año 1, No. 1, Enero-febrero 1988, p. 7-56.

32. ___ "Producción de alimentos y desbalances macroeconómicos". Realidad económico-social, año 2, No. 11, Septiembre-octubre 1989, p. 437-455.

33. Rodríguez, Octavio, "La teoria del subdesarrollo de la CEPAL". Editorial Siglo XXI, México 1980, 361 p..

34. Saca, Nolvia, "Políticas de estabilización económica en paises subdesarrollados: un modelo aplicado a la economia salvadoreñan. Boletin de ciencias económicas y sociales, año X, No. 3, mayo-junio 1987, p. 143-184. 
35. y Roberto Rivera, "Políticas de estabilización y deuda externa en El Salvador". Boletin de ciencias económicas y sociales, año X. No. 5, septiembre-octubre 1987, p. 315-369.

36. Stewart, Mark B. y Kenneth F. Wallis, "Introducción a la econometria", Alianza Editorial, Madrid 1984, 268 págs.

37. Taylor, Lance, "Structuralist Macroeconomics: Applicable Models for the Third World". Basic Books, United States of America 1983, 234 p..

38. "Modelos macroeconómicos para los paises en desarroIIo". Fondo de Cultura Económica, México 1986, 358 págs.

39. Thirlwall, A. P. y M. Nureldin Hussain, "The Balance of Payments Constraint, Capital Flows and Growth Rate Differences Developing Countries". Fotocopias, p. 408-509 